\title{
Dagupan River Basin Exposure and Vulnerability Assessment of Buildings Extracted from LiDAR Derived Datasets
}

\author{
Annie Melinda Paz-Alberto, Jo Adrianne A. Espiritu, Kathrina Mapanao \\ Institute for Climate Change and Environmental Management, Central Luzon State University, Science City of Muñoz, \\ Philippines \\ Email: anniealberto@clsu.edu.ph,melindapaz@gmail.com, joadaresp@gmail.com,mapanao.kathrina@gmail.com
}

How to cite this paper: Paz-Alberto, A. M., Espiritu, J. A. A., \& Mapanao, K. (2020). Dagupan River Basin Exposure and Vulnerability Assessment of Buildings Extracted from LiDAR Derived Datasets. American Journal of Climate Change, 9, 454-479. https://doi.org/10.4236/ajcc.2020.94029

Received: September 22, 2019

Accepted: December 27, 2020

Published: December 30, 2020

Copyright $\odot 2020$ by author(s) and Scientific Research Publishing Inc. This work is licensed under the Creative Commons Attribution International License (CC BY 4.0).

http://creativecommons.org/licenses/by/4.0/

\section{Abstract}

The Philippines has a geographical and geological setting of a typhoon-prone country. Tropical cyclones have a high incidence of passing through the Philippine islands during the months of September to November with an average time overland at 11 hours north of $14.5^{\circ}$ contrasted to 20 hours south of $14.5^{\circ}$. Due to the frequent occurrence of typhoons and tropical cyclones in this country, most of the provinces of the Philippines experience flood-related disasters that affect the people, their livelihood and many infrastructures. It is deemed necessary for the Philippines to come up with strategies to prevent further damage to its people and their properties. In this study, through the use of important parameters such as earth observations, Light Detection and Ranging (LiDAR) and Geographic Information System (GIS), assessment of buildings in Dagupan, the Philippines with the possibility of being affected by floods during different typhoon scenarios was done. GIS overlay analysis of the CLSU Phil-LiDAR 1 Project outputs, the 3D building GIS database, and flood hazard maps was done for the assessment. One (1) meter resolution LiDAR Digital Elevation Models (DEMs), geo-tagged video captured data and high-resolution images in Google Earth were used for processing and analysis to produce a 3D building GIS database. HEC HMS and HEC RAS were used to develop flood models that were used to produce flood hazard maps with different hazard levels. The results of this study were the series of flood exposure maps and vulnerability maps with statistics at different rainfall scenarios. Moreover, the buildings that will be affected by flood in the area were quantified and these were categorized according to their type. It was observed that as the rainfall return period increases, the number of buildings predicted to be exposed and vulnerable to flood also increases. The houses, business establishments, government offices, hospitals and other building types that are at 
risk of being affected by the flood were counted. Through analysis, it was predicted that there is a higher risk of building exposure and vulnerability during the 100-year rainfall return period. Out of the 71,884 buildings extracted from the area, a predicted 69,214 buildings will be exposed to flood during the 100-year rainfall return period, 59,137 buildings, 9253 buildings, 824 buildings at low, medium and high flood hazard level, respectively. Moreover, a total of 9297 buildings are foreseen to be vulnerable to flood, 4614 buildings, 4368 buildings, 315 buildings at low, medium and high flood hazard levels, respectively. The maps produced through the study are a valuable asset for the development and preparedness of the community in the Dagupan floodplain. Warnings and other information on evacuation measures will be easier to disseminate through the use of the produced maps in this study.

\section{Keywords}

Geographic Information System, Flood, Database, Extraction, Hazard

\section{Introduction}

Throughout the years, the Philippines has been included in the routes of most, if not all, the typhoons in South East Asia. Due to its geographical location, the Philippines has been hit by typhoons every year making it one of the areas on earth most exposed to natural and man-made disasters (Grünewald and Boyer, 2013). Some typhoons are rather normal but others devastatingly affect the country and the Filipinos. Typhoons bring tons of water to the country and this in return causes a flood to a lot of areas in the Philippines. Due to the incidence of flooding in the Philippines, government and non-government agencies are aware that disaster management is a necessity for the country. Efficient disaster management could help prepare and save the lives of thousands of Filipinos from disasters and make the country less prone to destruction and losses.

In 2012, news broke that in 15 years Dagupan City was underwater due to the continuous rising of sea level and ground subsidence in the area (Cardinoza, 2012). Dagupan is a bustling coastal city that is situated at the eastern margin on the delta of Agno River lying one meter above sea level while the Pantal River flows through it (Prevention Web, n.d.). Moreover, the city was reported to have seven tributaries, which include the Mangueragday River, Tanap River, Dawel River, Calmay River, Pantal River, Patogcawen River and Bayaoas River (Visperas, 2016). Calmay River traverses Lucao, Carael, Tapuac, Poblacion Oeste, Calmay, Lomboy, Salapingao and Pugaro Suit; Pantal River passes through Pantal, Barangay 1, Barangay II and III, Pogo Chico, Pogo Grande, Lasip Grande, Malued, Bacayao Sur and Lasip Chico; Dawel River is along Dawel area; Tanap River is found in Bonuan Gueset; Mangueragday in Bonuan Binloc, Patogcawen is in Tambac, Bayaoas River goes across Mamalingling, Bolosan, Manguin and Sa- 
lisay (Visperas, 2016). Due to the bodies of water surrounding the area of Dagupan, flooding in the city is as normal as it gets during the wet season when the level of water increases.

Light Detection and Ranging, shortly known as LiDAR, is now a common tool for obtaining data for hazard mapping, urban development and surveying of all types of areas. LiDAR uses an airborne laser to point at the surfaces of the targeted area and as the beams of the light are reflected, a sensor collects and the range of reflected lights is measured. A collection of these reflected beams of light is called a point cloud that has three-dimensional spatial coordinates (latitude, longitude, and height) that corresponds to a particular point on the Earth's surface from which the laser pulse was reflected (National Ocean Service, 2015). LiDAR technology, as a major source of digital terrain information, made the production of flood hazard maps attainable and more accurate. LiDAR systems offer accuracy, precision, and flexibility for the examination of both natural and manmade environments during mapping (National Ocean Service, 2015). Through LiDAR the topography of Dagupan was assessed and this study produced the data that was used for the hazard analysis for the area.

A valuable risk reduction method requires the identification and mapping of flood-prone areas. Moreover, it is also important to understand the relationship of hazards, exposure and vulnerability to each other to make disaster prevention effective (Bureau for Crisis and Recovery, 2010). Flood hazard maps contain information that is vital for the development and planning of the area as well as for the preparation of natural calamities or disaster.

In this study, the mapping and assessment of buildings exposed and vulnerable to flood in the flood plains of Dagupan River basin in Pangasinan, Philippines were conducted and the generation of the 3D building GIS database that was used for the assessments was also presented. The assessments were done through GIS overlay analysis using the CLSU PHIL-LiDAR 1 Project flood hazard maps outputs and generated 3D building GIS database. This study focused on identifying the number of buildings exposed to different flood hazard depth at varying rainfall return periods.

The general objective of the study was to generate a 3D Building GIS database and to determine the exposure and vulnerability of the building (in terms of height) to flood hazard at varying rainfall return periods in Dagupan River basin. Specifically, this study aimed to generate a 3D building GIS database for the Dagupan River flood plains, map the buildings' exposure and vulnerability to flood hazards in Dagupan River basin floodplains using GIS and assess the buildings exposure and vulnerability to flood at different rainfall scenarios with varying intensity and duration.

\section{Materials and Methods}

\subsection{The Study Area}

The city of Dagupan (Figure 1) is found in Pangasinan (16 $\left.2^{\prime} 51^{\prime \prime N ~} 120^{\circ} 20^{\prime} 27^{\prime \prime} \mathrm{E}\right)$, 


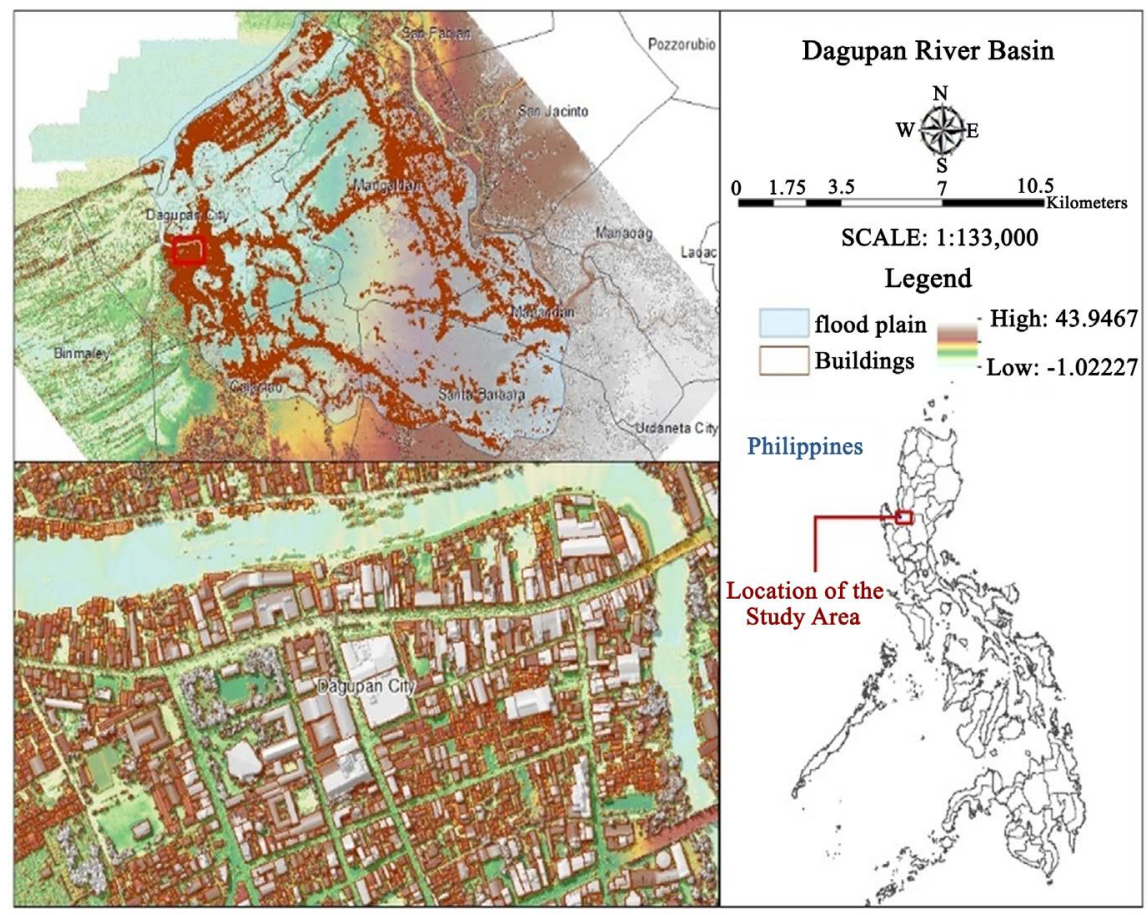

Figure 1. The Dagupan river basin in Pangasinan, Philippines.

bounded by Lingayen Gulf in the north, San Fabian in the northeast, Mangaldan in the east, Calasiao in the south and Binmaley in the west. The city has a total land area of 40,079,278.93 square meters or about 4008 ha, but cadastral maps reveal that the sum of lands within Dagupan is 4447.10 ha (Dagupan City, 2020).

A remarkable portion of the total area of Dagupan was composed of bodies of water such as rivers, lake, creeks, and fishponds, along with this is $35.98 \%$ of the area primarily for agriculture, $22.88 \%$ for residential and the rest are for the commercial, industrial, institutional, government parks and roads (Dagupan City, 2017). Dagupan has 31 barangays: Bacayao Norte, Bacayao Sur. Barangay II, Barangay IV, Bolosan, Bonuan Binloc, Bonuan Boquig, Bonuan Gueset, Calmay, Carael, Caranglaan, Herrero, Lasip Chico, Lasip Grande, Lomboy, Lucao, Malued, Mamalingling, Mangin, Mayombo. Pantal. Poblacion Oeste, Barangay I (T. Bugallon), Pogo Chico, Pogo Grande, Pugaro Suit, Salapinagao, Salisay, Tambac, Tapuac, and Tebeng (Philippine Statistics Authority, 2010).

\subsection{Dataset Utilized by the Study}

The LiDAR-derived Digital Surface Model (DSM) and Digital Terrain Model (DTM) with 1-m resolution acquired and processed by UPD PHIL-LiDAR 1 project were used for the extraction of building footprints in the flood plains of Santo Tomas River basin. These Digital Elevation Models (DEMs) have the Mean Sea Level as a vertical datum and were delivered in ESRI GRID format with Universal Transverse Mercator (UTM) Zone 51 North projection and the World Geodetic System (WGS) 1984 as horizontal reference (Santillan et al., 2015). 1D maps produced were obtained from the project Phil-LiDAR1 maps of 
the LiDAR Data Processing and Validation in Luzon: Region III and Pangasinan (Region I).

For improved accuracy in building footprints extraction, Google Earth images were utilized in rechecking of the existence and shapes of the extracted features from LiDAR DSM where created fishnet of rectangular cells was overlaid and served as a guide in both building footprint extraction and existence rechecking in Google Earth.

Extracted building features were also verified and field validated with the use of a video-tagging device or geotagged video capturing tool wherein information such as name and type were gathered. The provided table from the UPD PHILLiDAR 1 project containing a summary of different types of buildings with corresponding codes for the building type attributes.

The flood depth maps generated by the CLSU PHIL-LiDAR1 project were used as input in buildings flood exposure and vulnerability assessment. These flood depth maps represent the maximum depth of flooding due to rainfall events with varying intensity and duration (i.e. return period of 5, 25 and 100-year). Flood depth maps were transformed into flood hazard maps by categorizing the flood depths in hazard levels as follows: not exposed, low $(<0.5 \mathrm{~m}$ depth), medium (0.5 - $1.5 \mathrm{~m}$ depth) and high ( $>1.5 \mathrm{~m}$ depth). To determine the reliability and accuracy of the generated flood depth map to the observed flood depths in the area, field validation was conducted. Based on the results of the data from the field, the models had indicated a positive bias with an RMSE value of 0.84 which signifies that the generated flood hazard maps can produce a reliable exposure and vulnerability assessment.

\subsection{Generation of Building GIS Database}

\subsubsection{Building Feature Extraction}

For a more accurate number of buildings in the study area, features were manually digitized where footprints were traced using the polygon feature type from the LiDAR Digital Surface Model using ArcGIS 10.2 software. The existence and shape of the extracted buildings were checked using the corresponding high-resolution Google Earth due to the reason that some buildings and their extents were indistinguishable in the DSM.

\subsubsection{Building Feature Attribution}

All building features extracted were attributed following the various building types as shown in Table 1. With the use of the integrated Spatial Analyst in GIS, automated buildings height extraction from normalized Digital Surface Model (NDSM) was performed. The normalized DSM represents the height of the object from the terrain which was produced with the difference between the Digital Surface Model (DSM) and the Digital Terrain Model (DTM). The building height range that was considered is greater than or equal to $2 \mathrm{~m}$. Therefore, a digitized building with a height of less than $2 \mathrm{~m}$ was deleted. This assumes that only those features which are having the said height are considered as buildings. 
Table 1. Building types with corresponding codes that were used in the buildings attribution (UP-PHIL-LiDAR).

\begin{tabular}{|c|c|}
\hline Building Type & Code \\
\hline Agricultural \& Agro-Industrial & AG \\
\hline Bank & $\mathrm{BN}$ \\
\hline Barangay Hall & $\mathrm{BH}$ \\
\hline Factory & FC \\
\hline Fire Station & FR \\
\hline Gas Station & GS \\
\hline Market/Prominent Stores & MK \\
\hline Medical Institution & $\mathrm{MD}$ \\
\hline Military Institution & ML \\
\hline NGO/CSO Offices & NG \\
\hline Other Commercial Establishments & OC \\
\hline Other Government Offices & OG \\
\hline Police Station & $\mathrm{PO}$ \\
\hline Power Plant/Substation & PP \\
\hline Religious Institution & $\mathrm{RL}$ \\
\hline Residential & RS \\
\hline School & SC \\
\hline Sports Center/Gymnasium/Covered Court & SP \\
\hline Telecommunication Facilities & TC \\
\hline Transport Terminal (Road, Rail, Air, and Marine) & TR \\
\hline
\end{tabular}

\subsection{Generation of Flood Hazard Maps}

Through the CLSU PHIL-LiDAR 1 project, flood depth maps were generated and used as input in building flood exposure and vulnerability assessment in the flood plains of the Dagupan River basin. The flood depth maps were generated by the use of the developed flood model of the river basin from the combined HEC HMS hydrological model and HEC RAS hydraulic model. The flood depth maps represent the maximum depth of flooding due to rainfall events with varying return periods (5-, 25-, and 100-year return periods) where the discharges or flow data inputs were computed 5-, 25- and 100-year return period of rainfall events in the Dagupan River watershed. Flood depth maps were transformed into flood hazard maps by categorizing the flood depths into hazard levels as low (<0.50 m depth), medium (0.50 m - $1.50 \mathrm{~m}$ depth), and high ( $>1.5 \mathrm{~m}$ depth). Figure 2 displays the Dagupan flood hazard maps at a 5-year, 25-year and 100-year return period, respectively.

\subsection{Buildings Exposure Vulnerability Assessment}

GIS overlay analysis of the 3D building GIS database and flood hazard maps for 


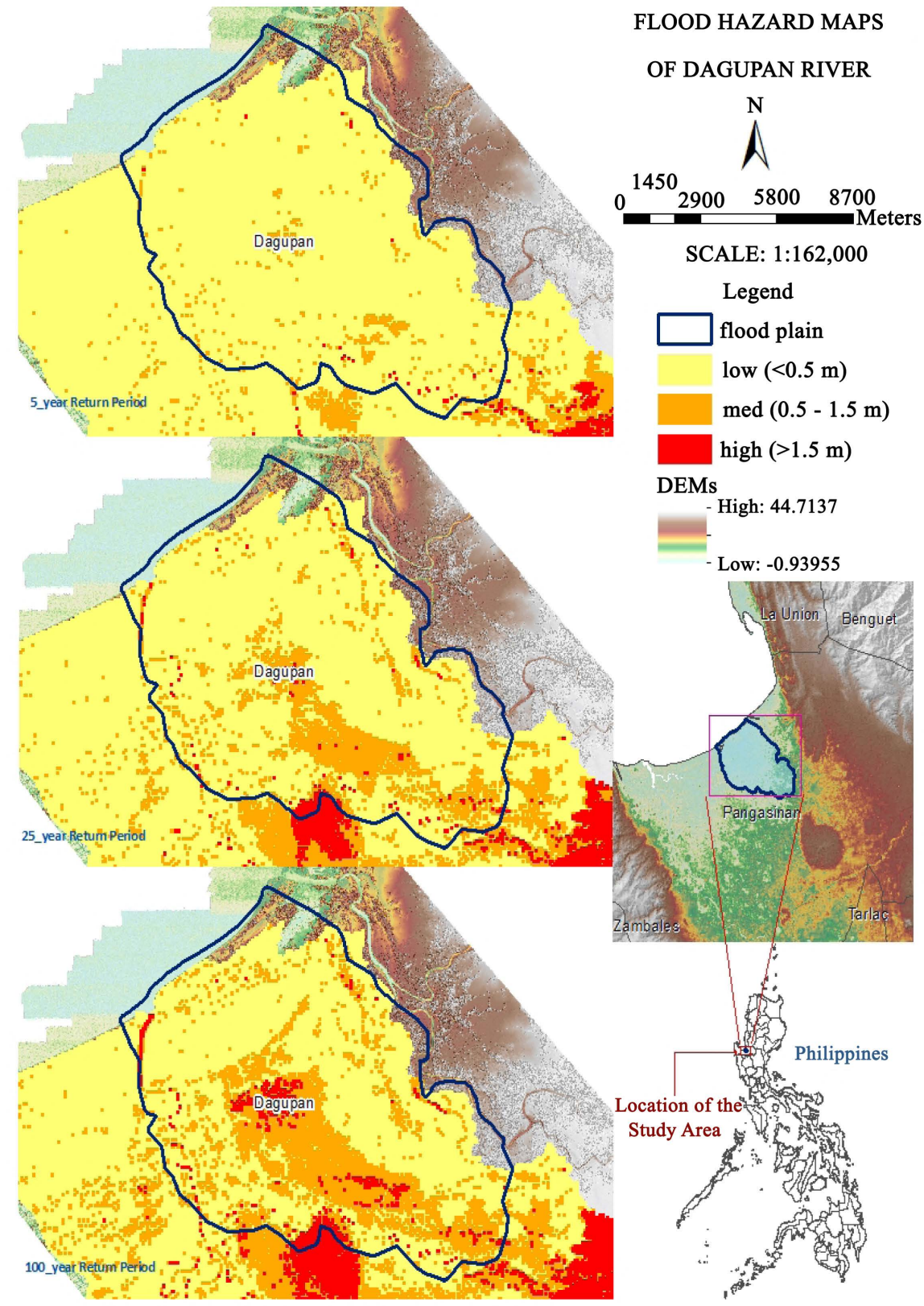

Figure 2. The flood hazard maps of Dagupan River at varying rainfall return periods.

the Dagupan river basin was conducted to identify which buildings are exposed to various levels (low, medium, and high) of flood hazards. For the determination of buildings' vulnerability in the flood plains of the River basin, the degree of building exposure to the flood was characterized by the comparison of buildings height and simulated flood depths. If the flood depth was less than 0.10 percent of the building height, it was coded as "Not vulnerable". If the flood depth was 0.10 percent but less than 0.30 percent of the building, it was coded as "Low vulnerable". On the other hand, if the flood depth was equal to $0.30-0.50$ percent, then the vulnerability was medium. If the flood depth was greater than 0.50 percent of the building's height, then the vulnerability was high. 


\section{Results and Discussion}

\subsection{Land Uses}

\subsubsection{Existing Land Use}

There are at least eight (8) land uses within the A and D land and public forest of the watershed (Figure 3). A \& D area corresponds to $24,678.54$ ha allocated for agriculture, 7271.46 ha for built-up areas, 4338.95 ha for agroforestry, and 1037.45 ha for reforestation uses. The public forest was set aside for agroforestry (157.66 ha), enrichment planting (259.47 ha), reforestation (2296.69 a), and all areas above $50 \%$ with the topography of 1000 -masl protection forest $(5344.27$ ha) (DENR Alaminos Regional Office, 2013).

\subsubsection{Land/Vegetation Cover}

Dagupan (Sinocalan) River Watershed is predominantly covered by cultivated, annual crop with $24,428.68$ ha followed by the built-up area with (7271.46 ha) (Table 2 and Figure 4). It is also comprised of 4686.09 ha of wooded grassland, 3555.47 ha of the cultivated perennial crop, 1755.92 ha of shrubs and 1285.94 ha of broadleaved open forest. The least area covered is the closed coniferous forest with only 47.96 ha (DENR Alaminos Regional Office, 2013).

\subsection{Hydrologic Hazard and Mass Movement Hazard}

\subsubsection{Flood}

Pangasinan, being situated in low-lying areas is prone to perennial flooding especially, along river tributaries. Dagupan (Sinocalan) River together with Agno River causes flooding in nearby municipalities. Figure 5 shows that 22,016.2 ha

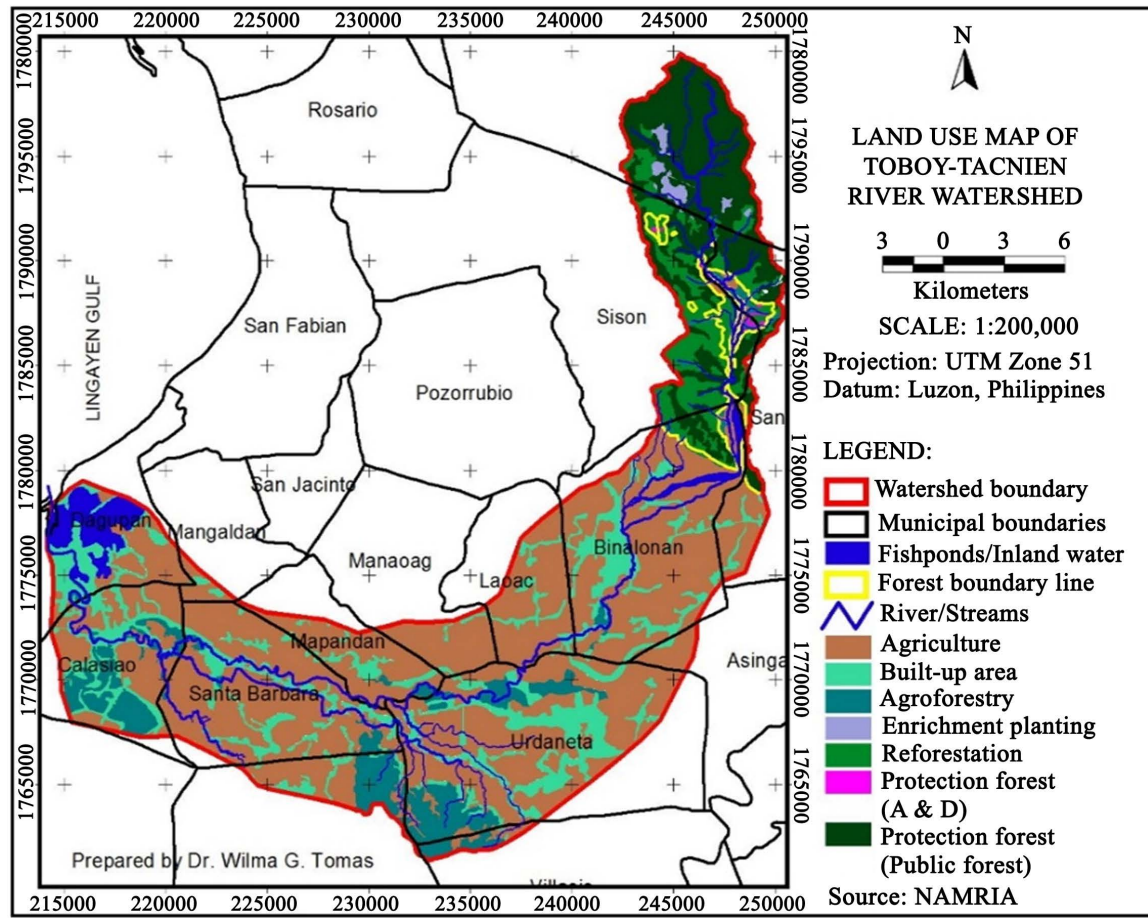

Figure 3. Land use map of Dagupan (Sinocalan) River Watershed. 


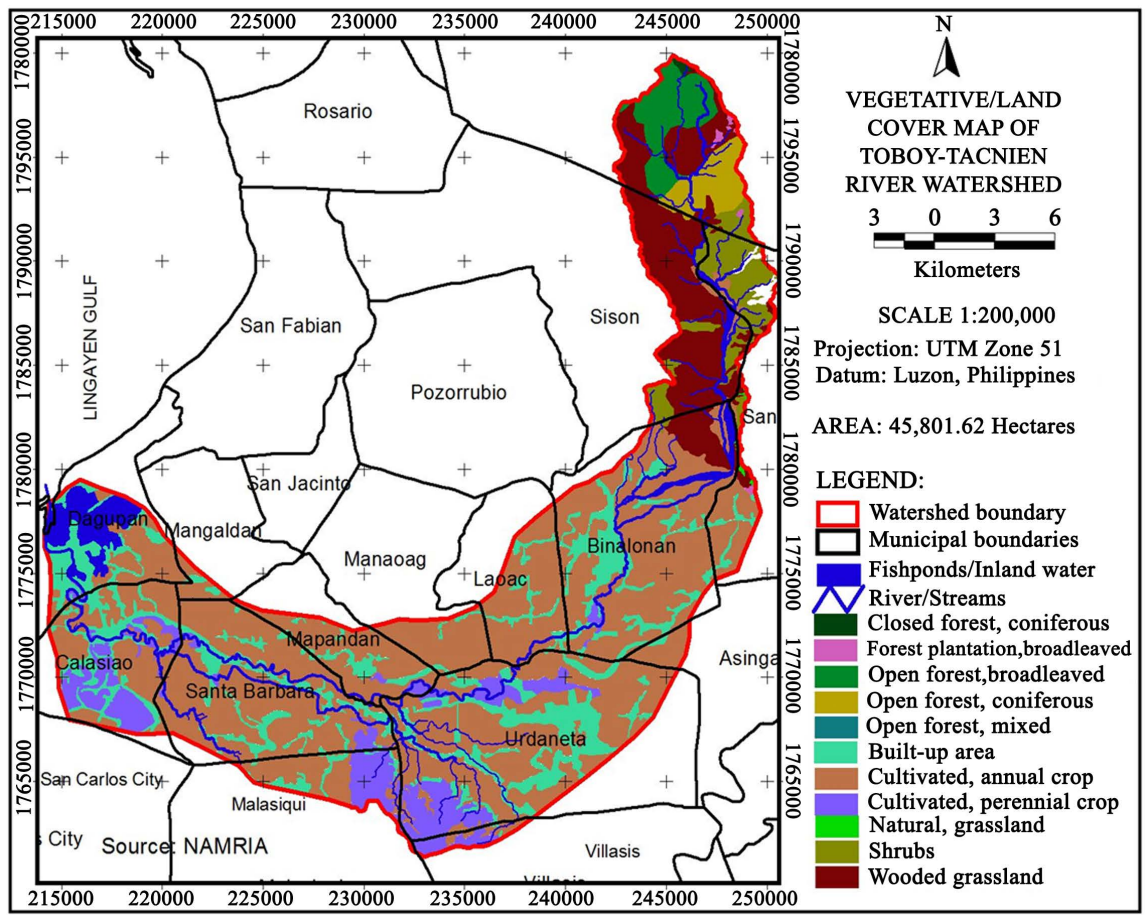

Figure 4. Vegetative/land cover map of Dagupan (Sinocalan River Watershed).

Table 2. Vegetation/land cover of Dagupan (Sinocalan) River watershed.

\begin{tabular}{cc}
\hline Vegetation/Land Cover & Area (ha) \\
\hline Cultivated, annual crop & $24,428.68$ \\
Built-up area & 7271.46 \\
Wooded grassland & 4686.09 \\
Cultivated, perennial crop & 3555.47 \\
Shrubs & 1755.92 \\
Open forest, broadleaved & 1285.94 \\
Fishpond & 983.00 \\
Open forest, coniferous & 893.99 \\
Inland water & 616.03 \\
Open forest, mixed & 155.29 \\
Forest plantation, broadleaved & 70.36 \\
Natural, grassland & 51.43 \\
Closed forest, coniferous & 47.96 \\
TOTAL & $45,801.62$ \\
\hline
\end{tabular}

Source: National mapping \& resource information authority.

of low-lying areas within the watershed are highly susceptible to flooding. Reckoned from the generated data of MGB DENR R-1 disclosed that Dagupan City has the most number of affected barangays ( 29 barangays) that are highly 


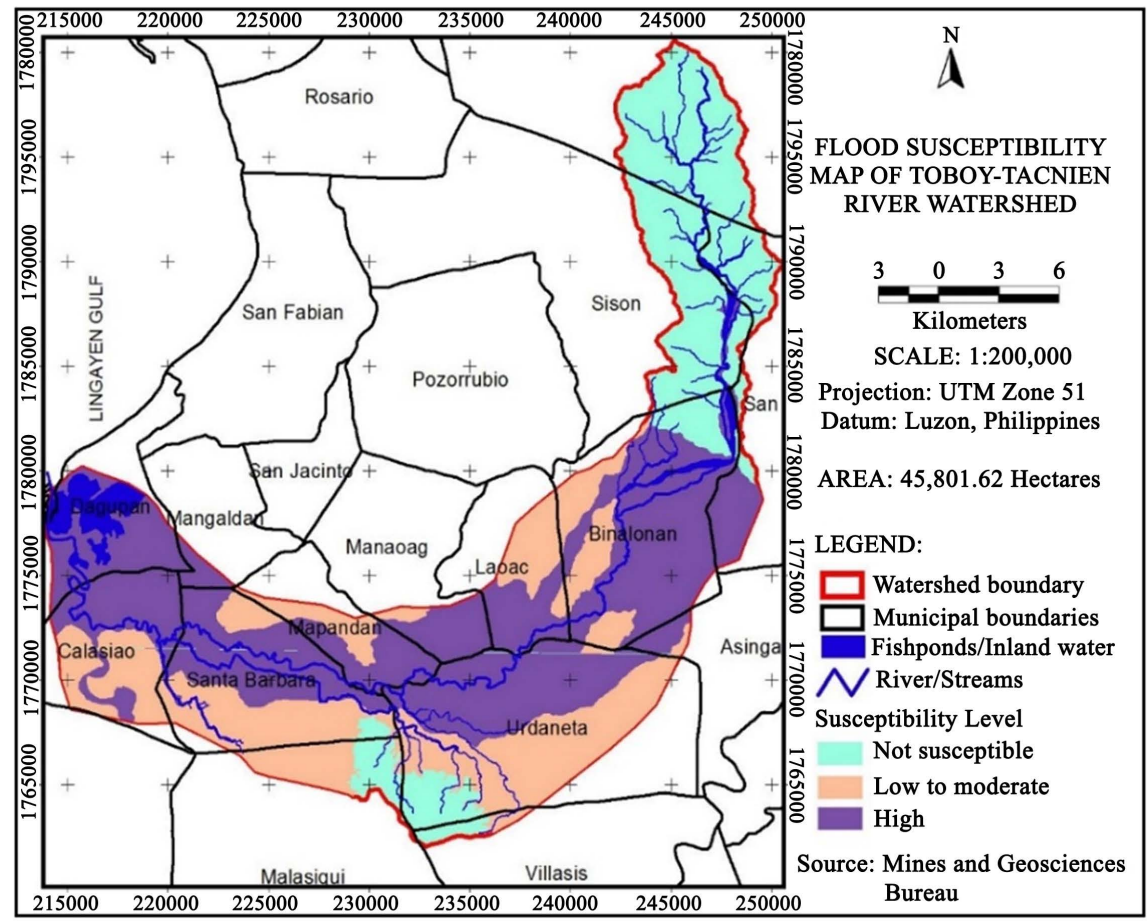

Figure 5. Flood susceptibility map of Dagupan (Sinocalan) River Watershed.

susceptible to flooding, followed by Sta. Barbara (26 barangays). Other municipalities that are highly susceptible to flooding include Binalonan (23 barangays), Calasiao (22 barangays), Urdaneta (19 barangays), Laoac (9 barangays), Manaoag (7 barangays), Asingan (4 barangays), Mangaldan, 4 barangays), Mapandan (4 barangays), and three (3) barangays in San Manuel (DENR Alaminos Regional Office, 2013).

There is also a report that severe floods in Dagupan for the last two decades have a ten-year recurrence interval (Ecosystems Research and Development Bureau, 2015). It was also reported that flooding was found to be mainly caused by the following: 1) physiography; 2) river and channel aggradation; and 3) heavy rainfall. The interviews conducted affirmed that the majority of respondents believed that the magnitude and frequency of flooding are increasing. Respondents also affirmed to have experienced annual flood with a water depth that varied from knee-to waist-deep. Most of the damages caused by flooding were in agriculture (e.g., crops and livestock) and infrastructure (e.g., buildings, schools, houses, bridges, and roads).

\subsubsection{Rain-Induced Landslide}

A landslide can be caused by a variety of factors including earthquakes, storms, volcanic eruptions, human modification of land, and by strong or heavy rainfall. In a landslide, masses of rock, soil or debris move down a slope (https://www.ready.gov/landslides-debris-flow). Debris and mud flows are rivers of rock, soil, and other debris saturated with water. They develop when water rapidly accumulates in the ground, during heavy rainfall, changing the soil into a 
flowing river of mud and they can flow rapidly

(https://www.ready.gov/landslides-debris-flow).

Landslide occurrences caused by prolonged or heavy rainfall has been experienced in the country especially in steep barren mountainous areas when the normal rainfall rate exceeds the normal absorptive capacity of the soil and triggered by abnormal volume of rainwater in a short period. Such catastrophe resulted in the loss of lives and damage to properties. The Toboy-Tacnien/Sinocalan River Watershed is also prone to a rain-induced landslide (Figure 6). Most of the barangays that are highly susceptible to landslide are located in the mountainous/steep slopes of San Manuel and Sison. Slightly susceptible to rain-induced landslide covers the municipalities of Binalonan, Malasiqui, San Manuel, Urdaneta City and Villasis as identified in the characterization report. There are also two (2) barangays that are moderately susceptible to landslide in Binalonan (Moreno and Sta. Catalina and one barangay in San Manuel (Barangay Lapalo) (DENR Alaminos Regional Office, 2013).

\subsection{1-D Simulated Flood Hazard Maps Due to Hypothetical, Extreme Rainfall Events}

The resulting model was used in determining the flooded areas that will be affected by extreme rainfall events. The simulated model was an integral part of determining real-time flood inundation extent of the river after it had been automated and uploaded on the DREAM website. The sample 1D flood hazard map using the calibrated discharge of Dagupan River from HMS model is shown in Figure 7.

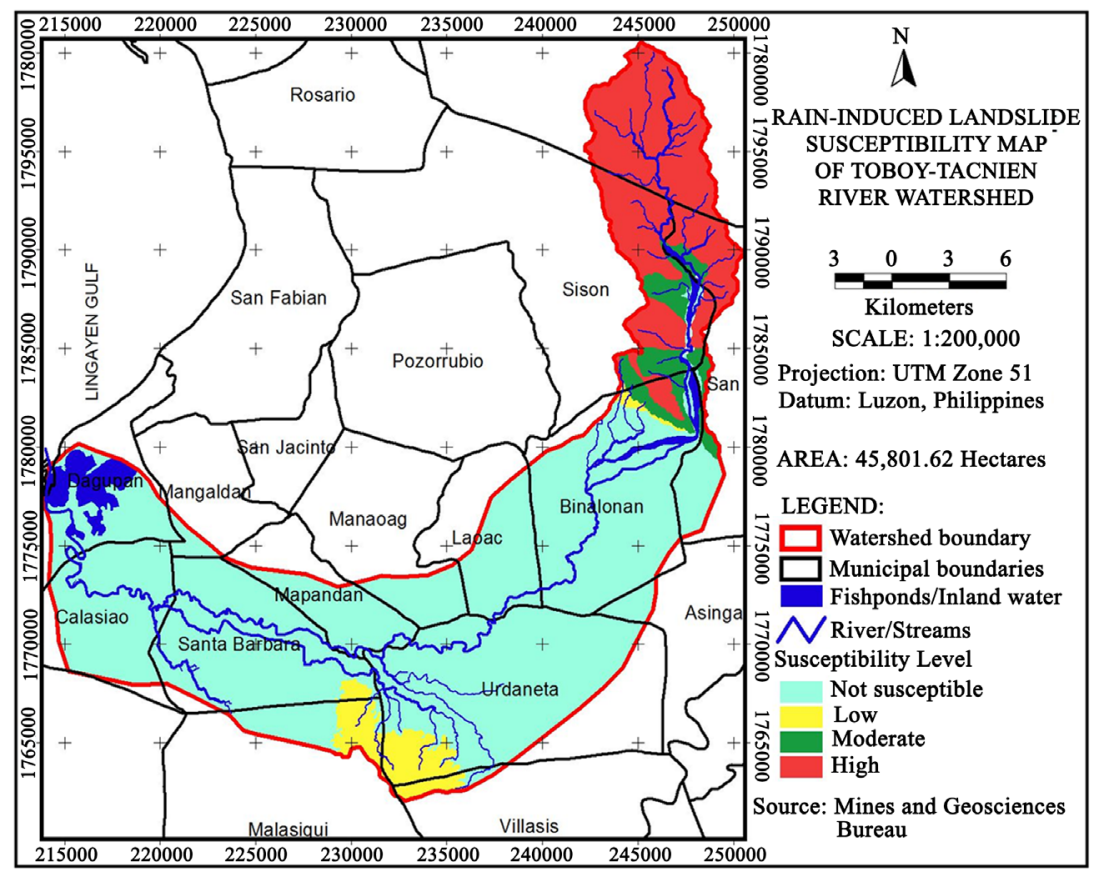

Figure 6. Rain-induced landslide susceptibility map of Dagupan (Sinocalan) River Watershed. 


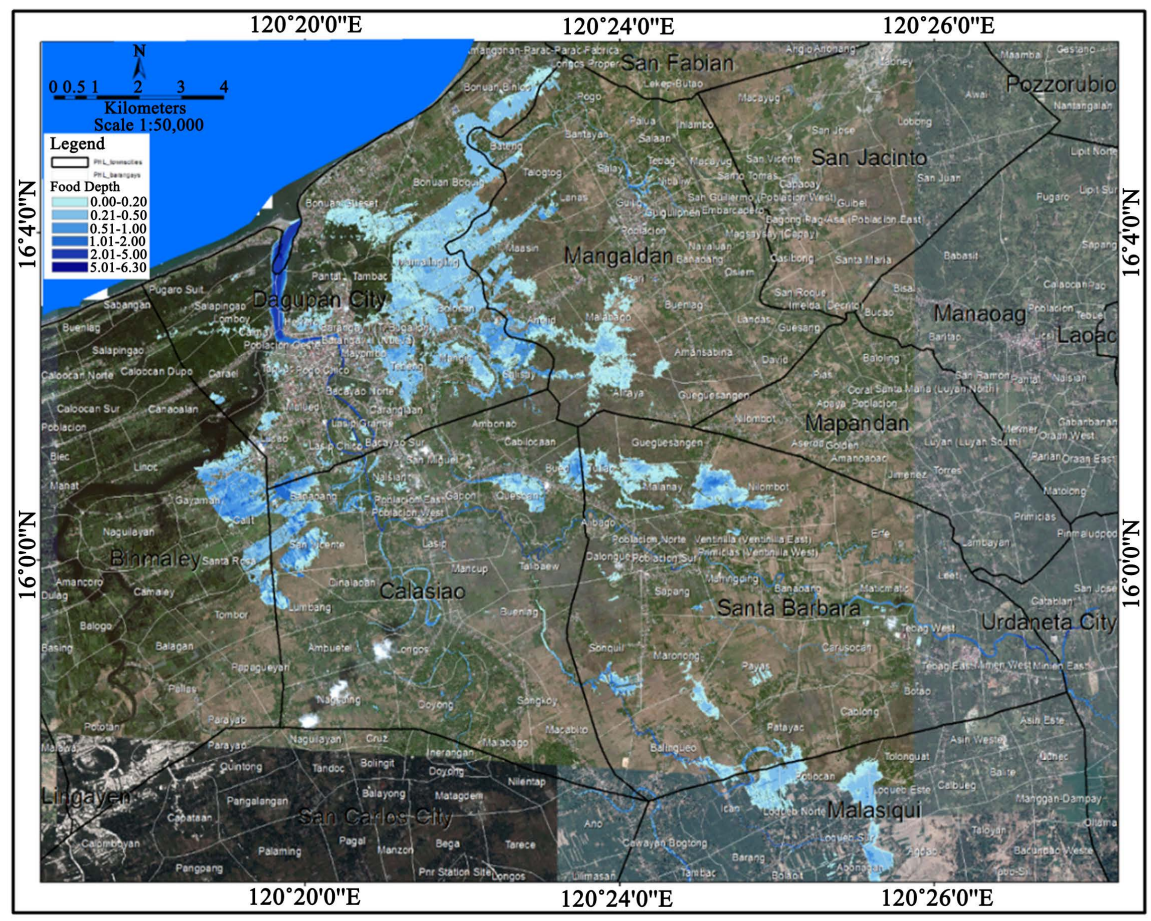

Figure 7. 1D Flood hazard map using calibrated flow discharge of Dagupan River from HMS.

Figures 8-12 show the 1-D simulated flood hazard maps of Dagupan River Basin for a 5-year, 10-year, 25-year, 50-year and 100-year rainfall events.

Dagupan City experiences most high level $(>1.5 \mathrm{~m})$ of flood at different rainfall periods as presented in Table 3. One reason is that the town is located in the downstream portion of the river which serves as the catchment basin in the area. Barangays Bolosan, Mangin, Tebeng, Salisay, Mamalingling, Bonuan Boquig, Pogo Chico, Malued, Bacayao Sur and Lucao could experience low to high flood events at different rainfall return periods. Dagupan City will experience high flooding in case a 5-year return rainfall event will occur in an estimated area of 902.71 ha (Figure 8). However, for a 10-year return rainfall event, an estimated area of 1085.66 ha will experience high flooding (Figure 9) whereas for a 25-year rainfall return event an estimated 1322.42 ha will be affected (Figure 10). Moreover, for a 50-year return rainfall event, an estimated area of 1472.62 ha will experience great flood (Figure 11) while 1610.55 ha for a 100-year return rainfall event (Figure 12).

\subsection{GIS Building Database}

Using ArcGIS, LiDAR data were processed and buildings from the floodplains of Dagupan were extracted (Figure 13). The GIS shapefile of the Dagupan floodplain consisted of 71,884 buildings which were further subdivided to its type (Figure 14). Out of the total buildings in the area, $96.71 \%$ were recognized as residential buildings while the least proportion of the buildings were identified as Telecom facilities, non-government offices, water supply, fire stations, etc. 


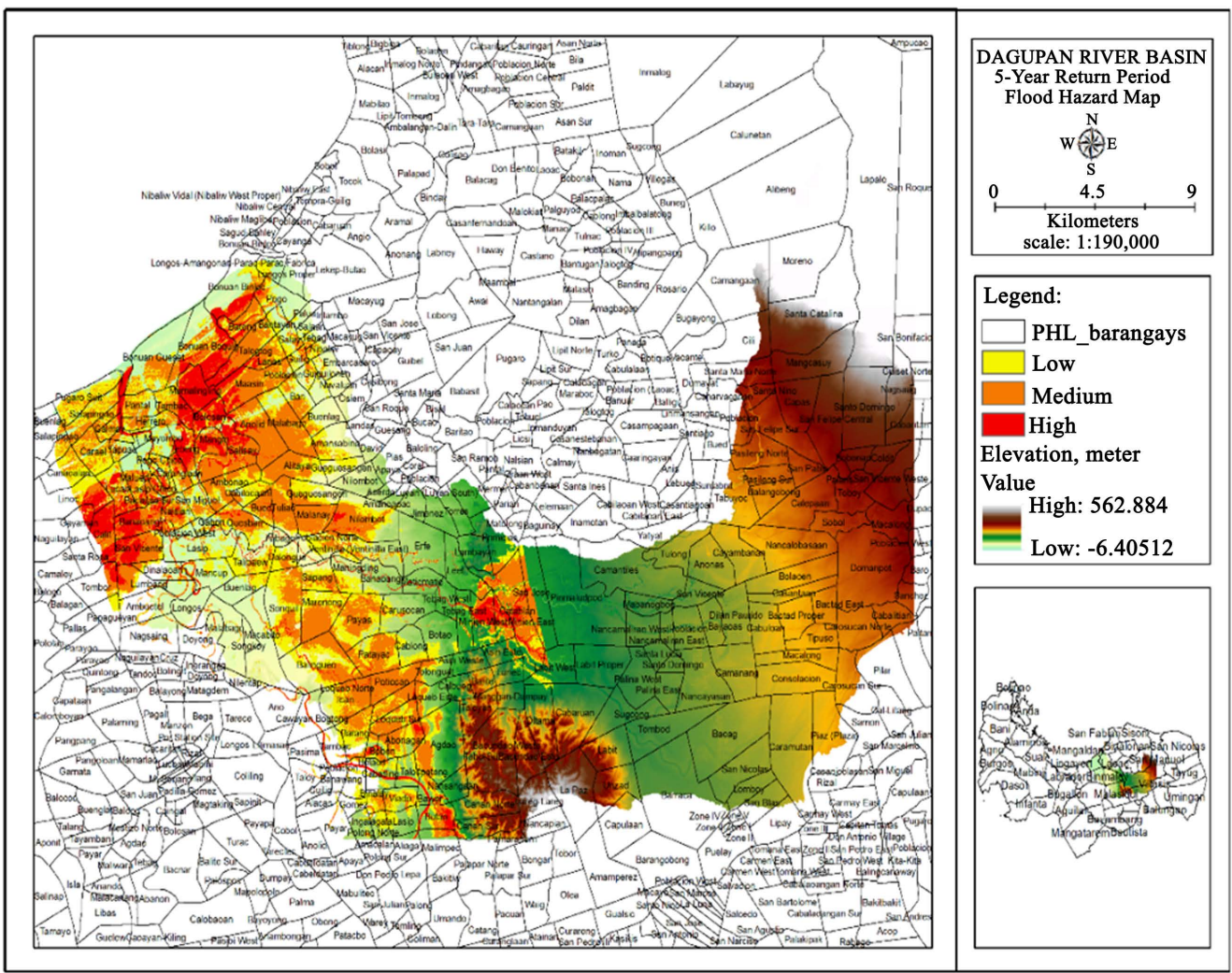

Figure 8. 1D-Simulated flood hazard map of Dagupan River Basin for a 5-year rainfall event.



Figure 9. 1D-Simulated flood hazard map of Dagupan River Basin for a 10-year rainfall event. 
A. M. Paz-Alberto et al.

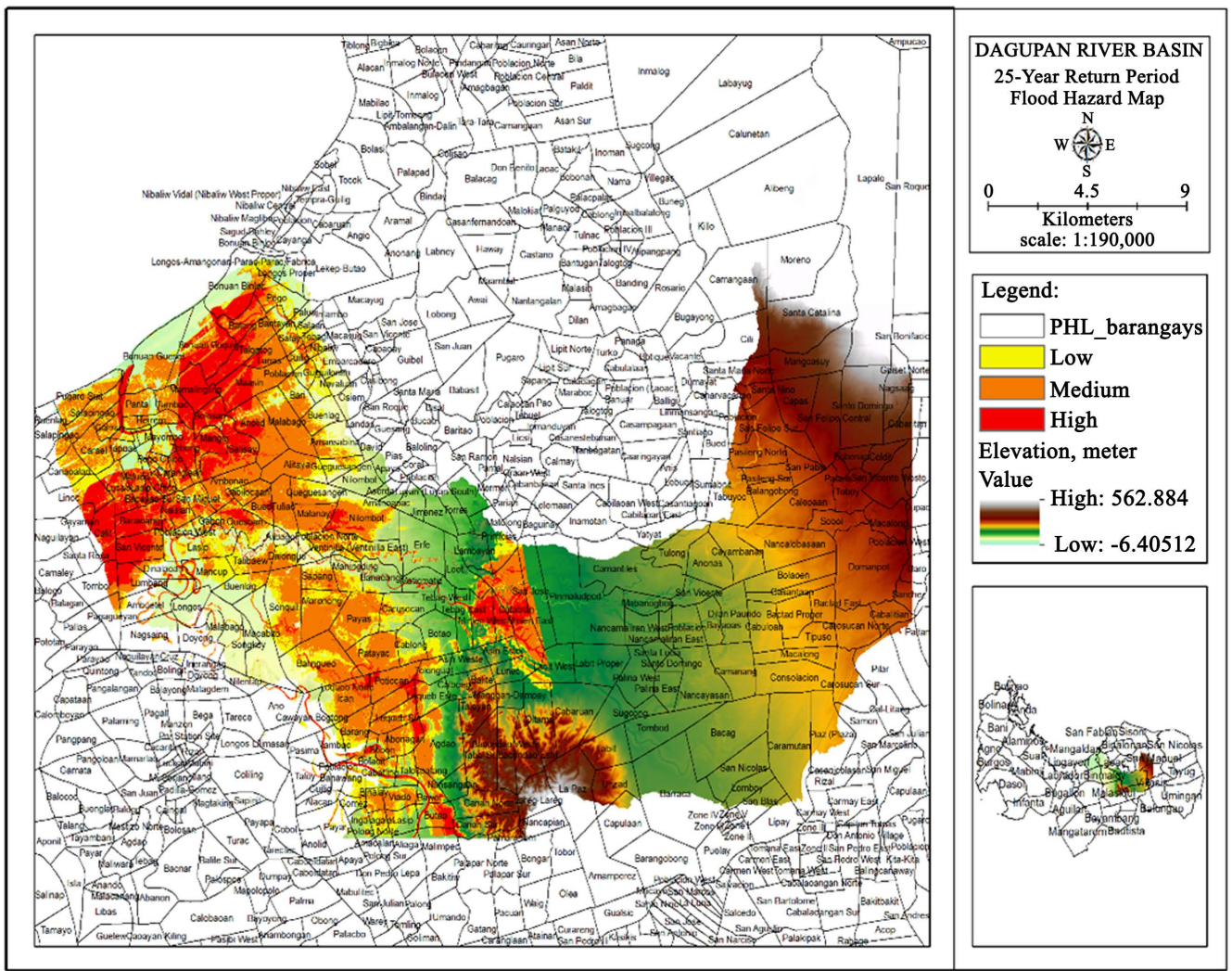

Figure 10. 1D-Simulated flood hazard map of Dagupan River Basin for a 25-year rainfall event.

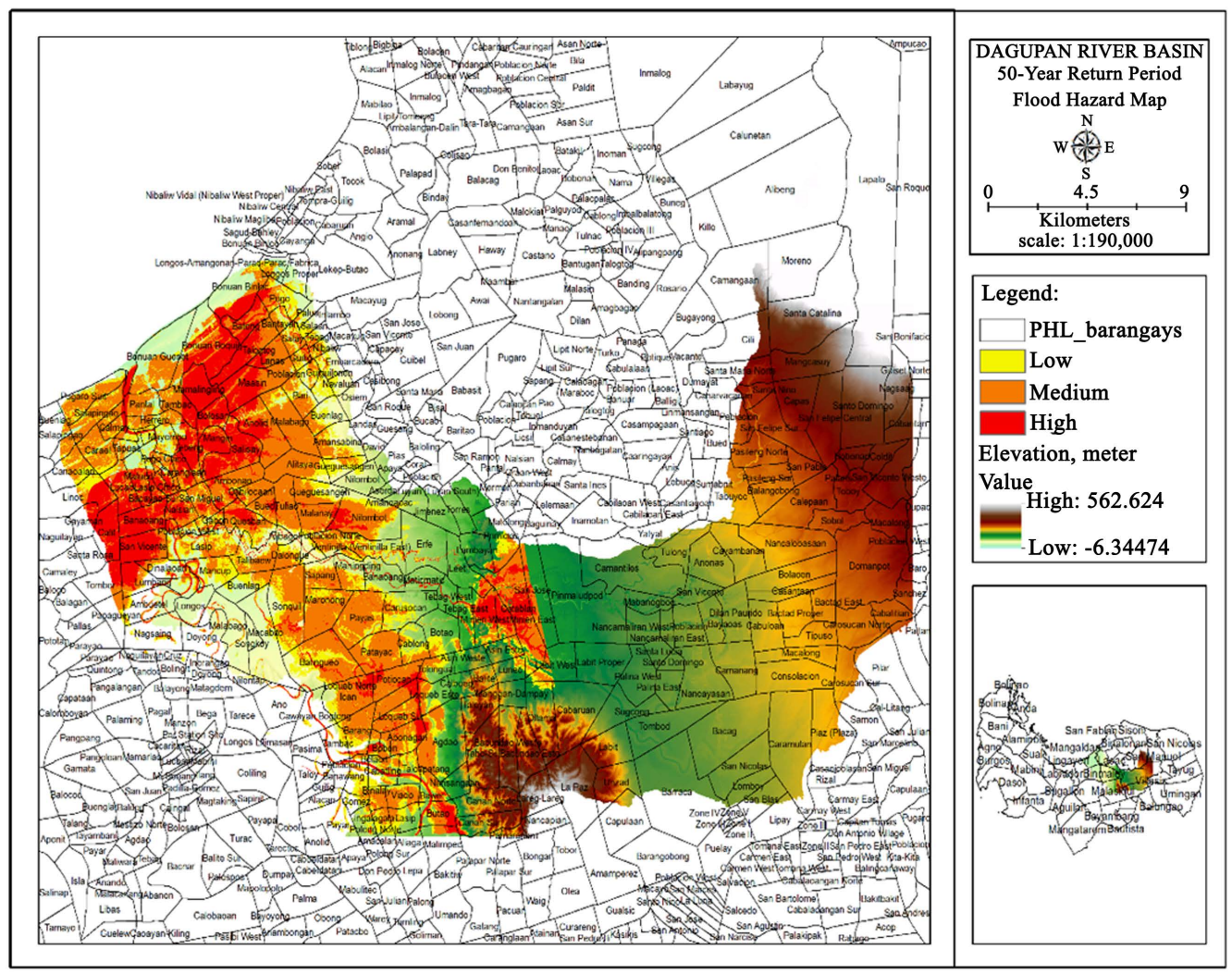

Figure 11. 1D-Simulated flood hazard map of Dagupan River Basin for a 50-year rainfall event. 


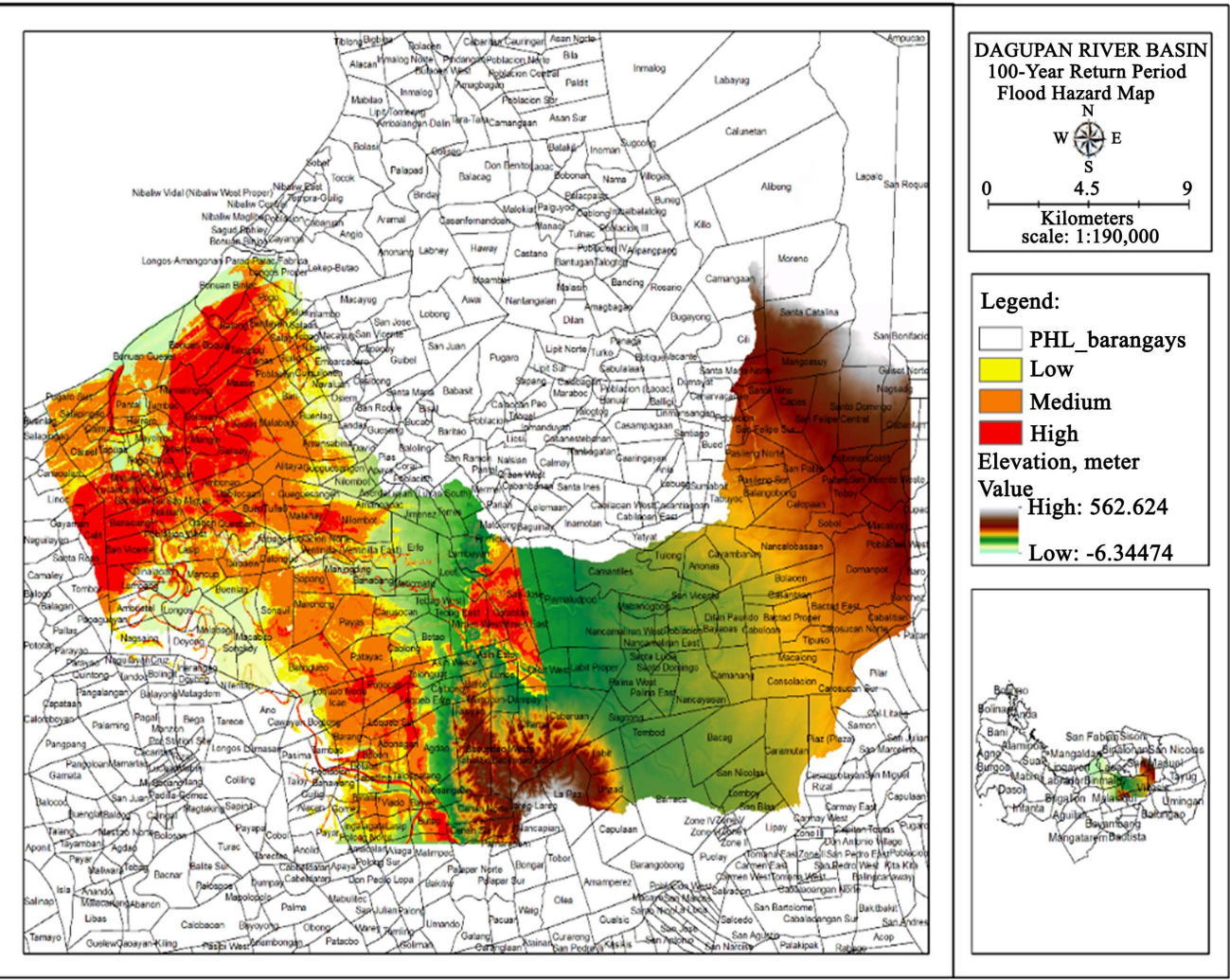

Figure 12. 1D-Simulated flood hazard map of Dagupan River Basin for a 100-year rainfall event.

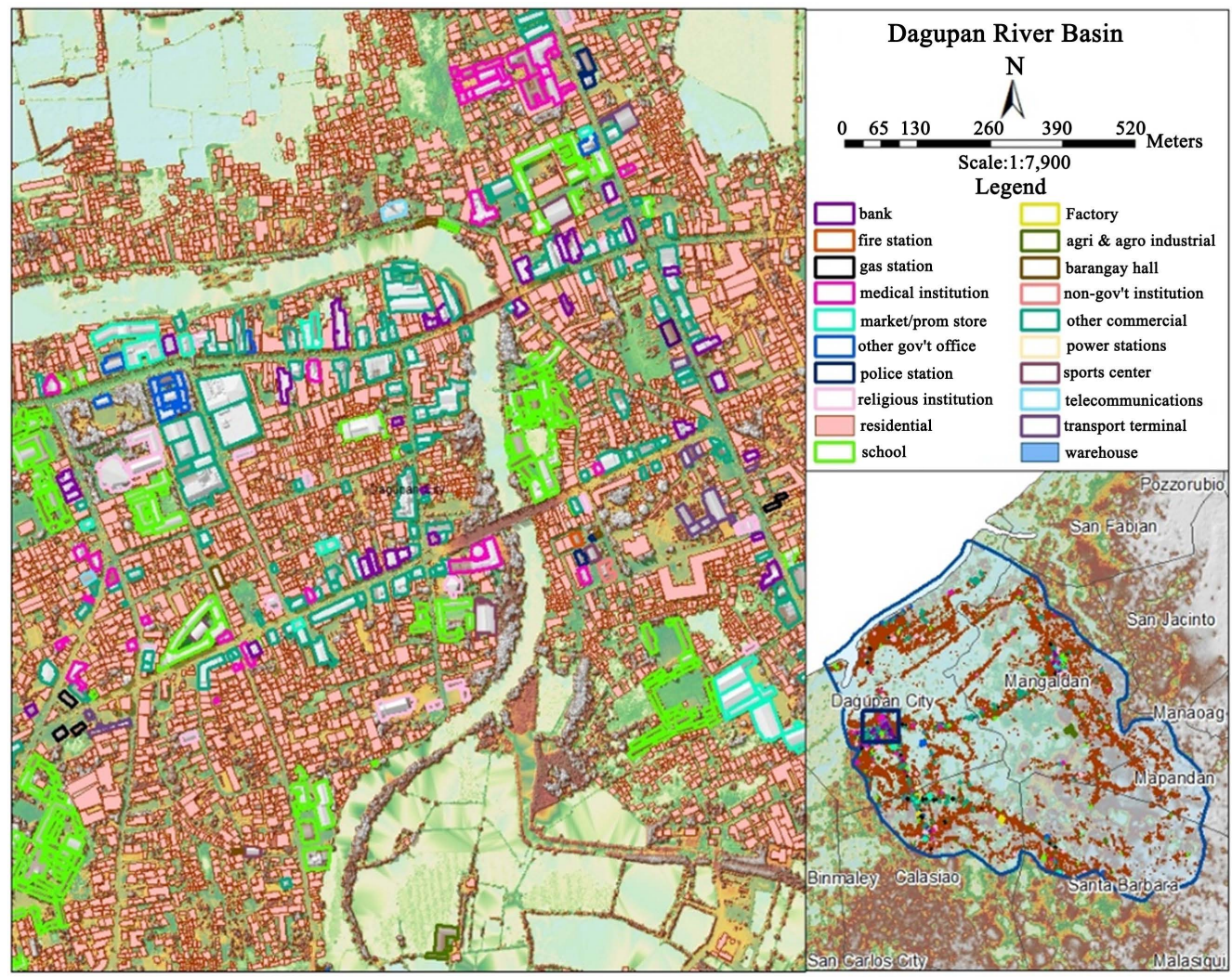

Figure 13. The extracted building footprints in the flood plains of Dagupan River. 


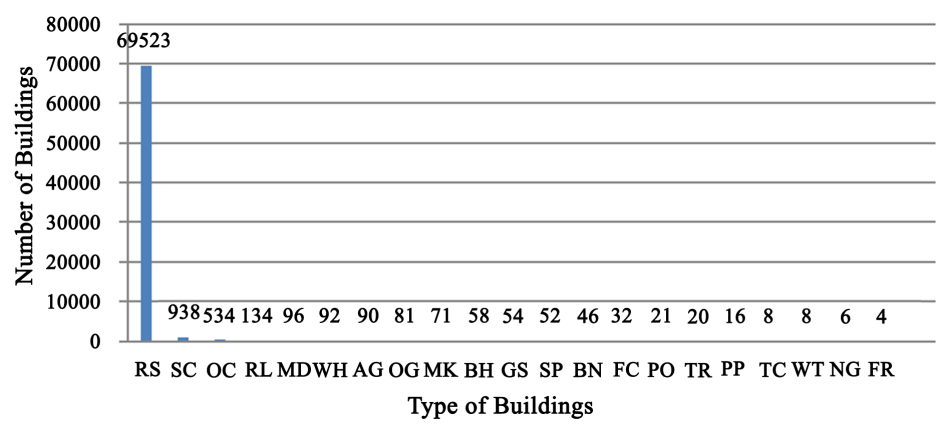

Figure 14. Extracted buildings with attributes in Dagupan River flood plain according to type.

Table 3. Areas (hectare) of Dagupan City that will be affected by flood at different return periods.

\begin{tabular}{ccc}
\hline RIDF & Category & Areas (ha) in Dagupan City Affected By Flood \\
\hline \multirow{3}{*}{ 5-year } & Low & 1064.53 \\
& Medium & 1466.22 \\
& High & 902.71 \\
10-year & Low & 924.44 \\
& Medium & 1505.79 \\
& High & 1085.66 \\
25-year & Low & 673.61 \\
& Medium & 1612.79 \\
& High & 1322.42 \\
& Low & 543.05 \\
& Medium & 1655.08 \\
& High & 1472.62 \\
& Low & 475.07 \\
& Medium & 1650.91 \\
& High & 1610.55 \\
& &
\end{tabular}

Figure 14 shows that among the extracted different building types, the most number of buildings (69.523 buildings) are categorized as a residential type while the least was attributed as under Fire station type of building. It shows that Dagupan River is mostly surrounded by residential buildings along its bank.

\subsection{Building Exposure to Flood Hazard}

Floods are prevalent in Dagupan City during the wet season in the Philippines. Different types of buildings are seen and experienced to be exposed to flood whenever the city is hit by typhoons. Quantified results of the exposure of the different buildings to flood hazards in the flood plains of Dagupan, Pangasinan are proportioned in Figure 15. In a 5-year rainfall return period, only $7.62 \%$ of 


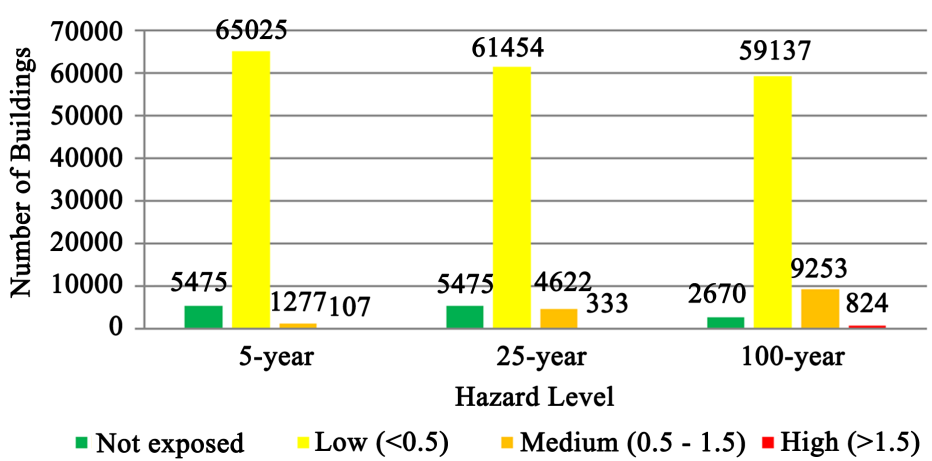

Figure 15. The number of buildings exposed to different hazard levels at varying rainfall return periods.

all the buildings (5475 buildings) were predicted to be unexposed to flood. However, $90.46 \%$ of the buildings (65,025 buildings) were predicted to be exposed under low flood $(<0.5 \mathrm{~m})$ while $1.78 \%$ of the buildings (1277 buildings) were predicted to be exposed to medium flood $(0.5-1.5 \mathrm{~m})$ and the remaining $0.15 \%$ (107 buildings) will be exposed to high flood $(>1.5 \mathrm{~m})$. The same trend was seen in a 25 -year rainfall period. The unexposed buildings to flood in a 25 -year rainfall return period remained at $7.62 \%$ of the total number of the buildings during this time. Further at a 100-year rainfall return period, there was a slight decrease in the percentage of buildings that were predicted to be exposed to different hazard levels resulting in an increase in the number of those that are going to be exposed. Exposed buildings under low flood hazard levels were at $85.49 \%$ (61,454 buildings), under medium flood hazard levels were at $6.43 \%$ (4622 buildings) and under high flood hazard levels were at $0.46 \%$ (333 buildings). In a 100-year rainfall return period, the number of buildings unexposed to the flood was predicted to drop at $3.71 \%$ (2670 buildings) while the number of buildings exposed to flood will increase. It was predicted that buildings that will be exposed to flood are at $82.72 \%$ (59,137 buildings) for low level, $12.87 \%$ (9253 buildings) for medium level and 1.15\% (824 buildings) for a high level during the 100 -year rainfall return period.

The predictions indicated that throughout the recognized rainfall return periods, buildings flood exposure will eventually increase where buildings become more susceptible to flood. Increasing flood exposure of buildings is depicted in Figures 16-18 showing the locations of the expected affected buildings around Dagupan during a 5-, 25- and 100-year rainfall return period, respectively.

The severity of buildings exposed to flood is shown as the orange (medium level) and red (high level) colors diffuse in the maps. Figure 19 shows the total number of buildings on the different rainfall return period (5-, 25, 100-year rainfall return period) according to the building types. Among the exposed buildings to flood, residential-type buildings are mostly affected followed by schools, and other commercial establishments. Meanwhile, the rest of the building types fell on the side of the graph since these are far less in number compared to the occurrence of residential building types in the area. Results revealed 


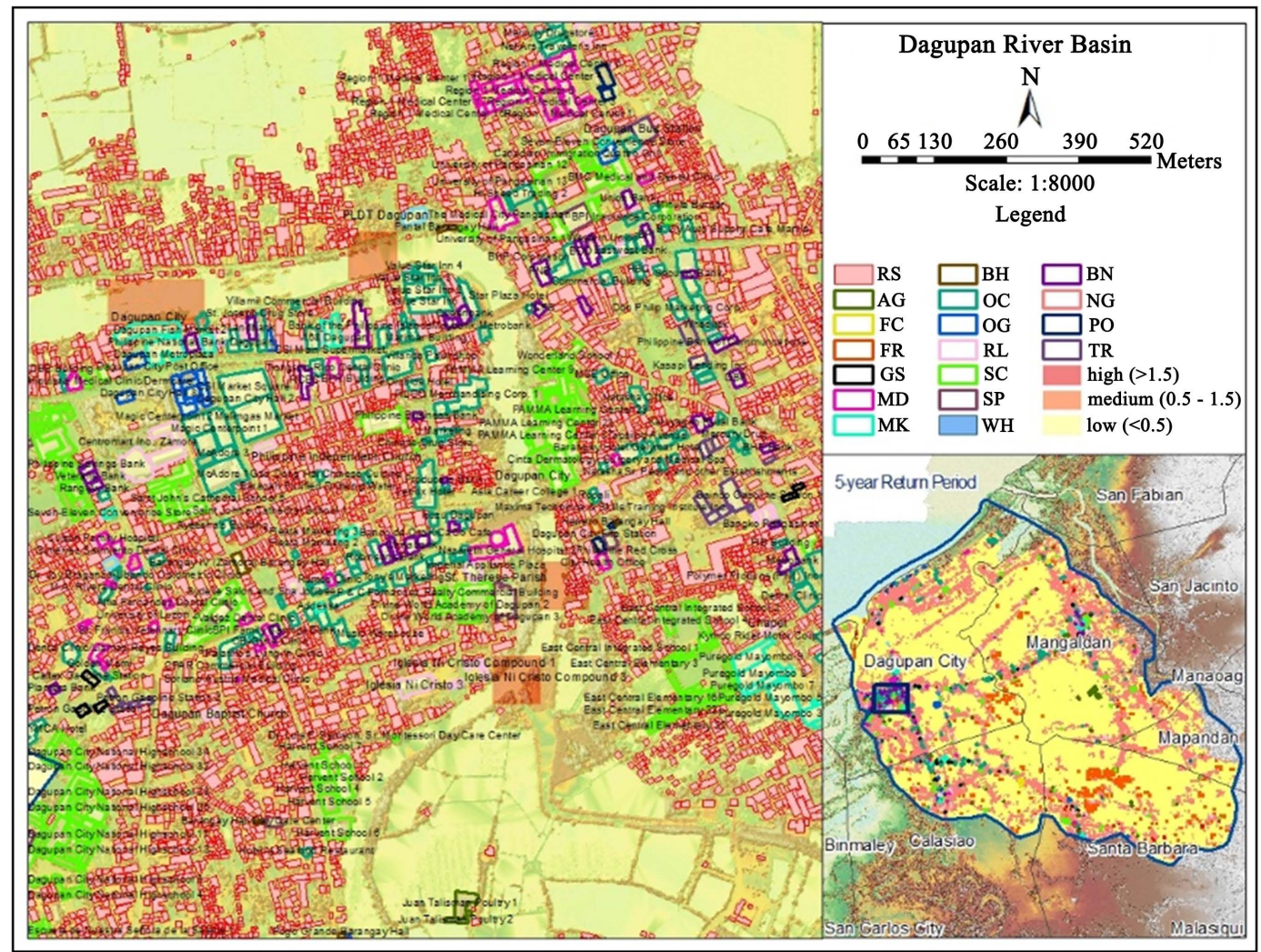

Figure 16. Location of buildings exposed to flood hazard at 5-year return period of rainfall event.

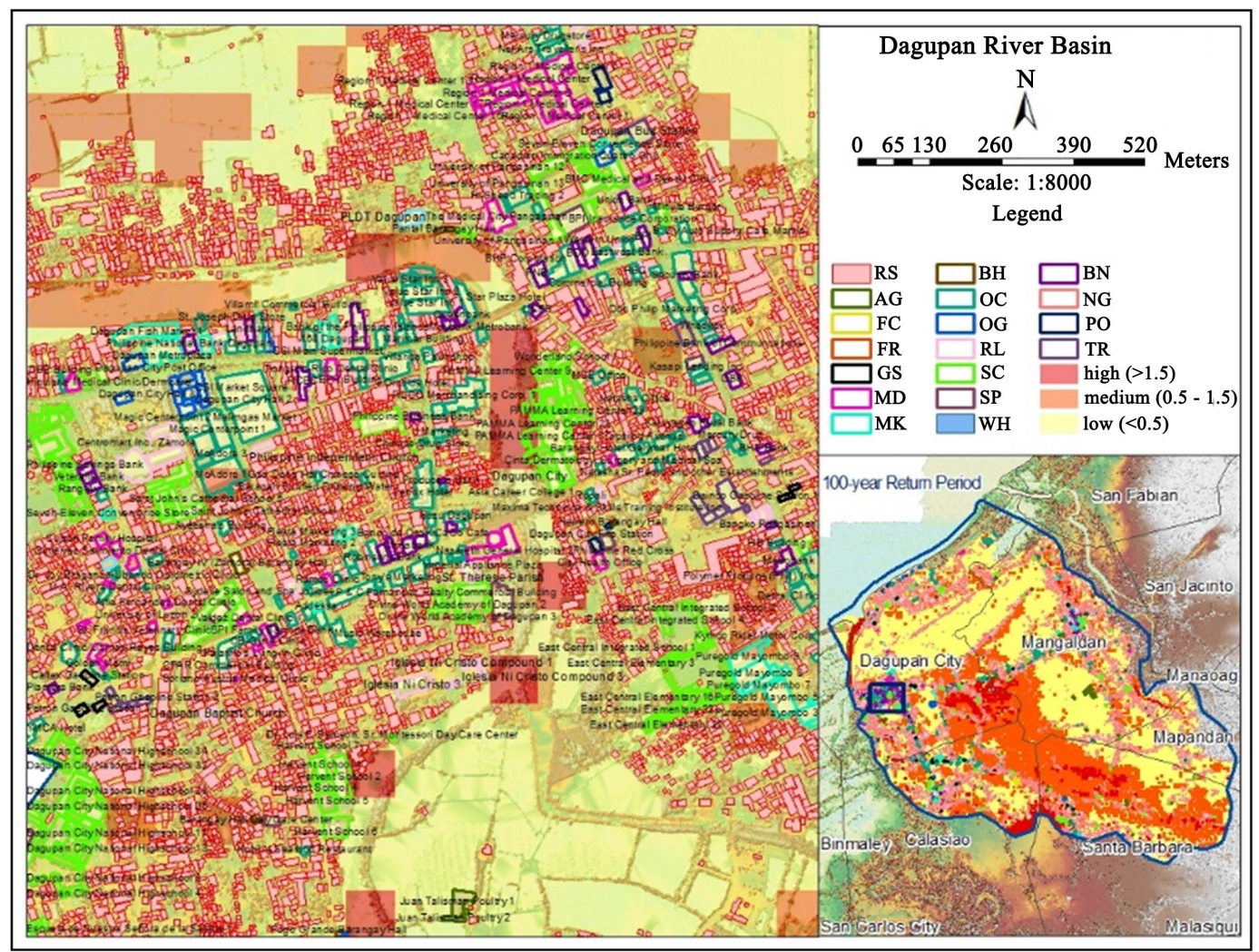

Figure 17. Location of buildings exposed to flood hazard at 25-year return period of rainfall events. 


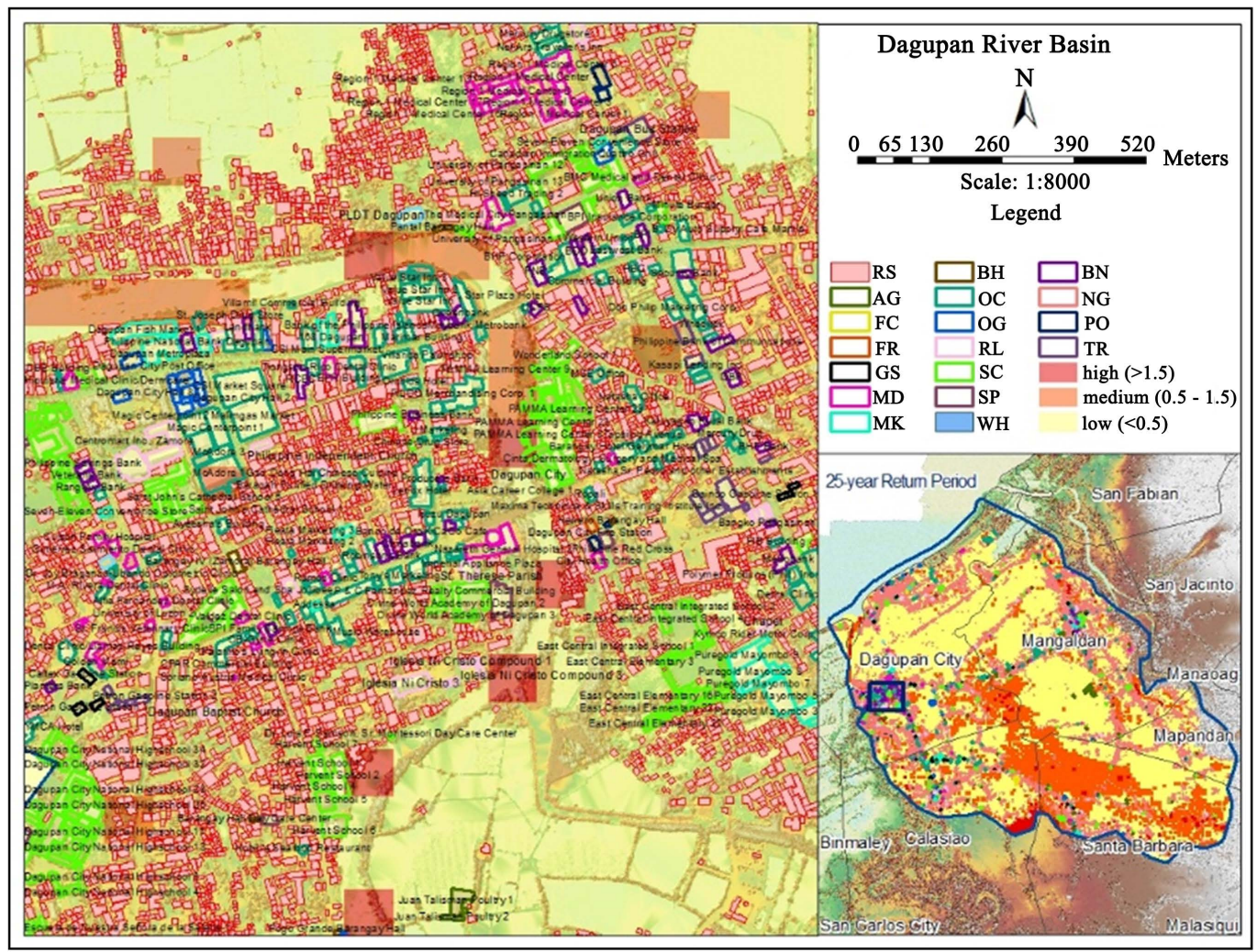

Figure 18. Location of buildings exposed to flood hazard at 25-year return period of rainfall events.

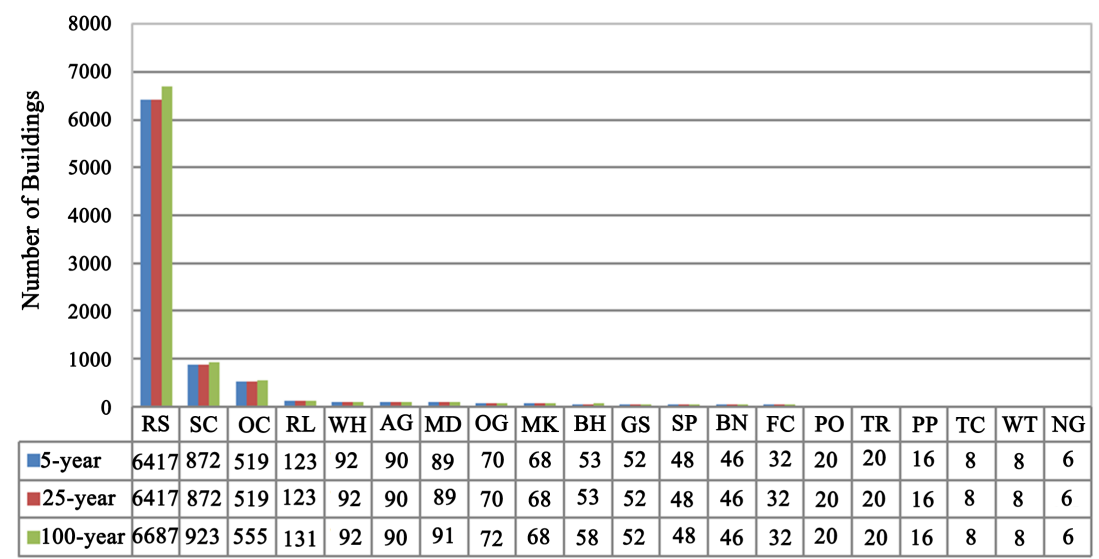

Type of Buildings

Figure 19. The number of buildings exposed to flood hazard according to type at varying rainfall return period.

that as time reaches a hundred years, buildings increases. The types of buildings that may increase in number and appear in time include residential, school, medical institutions, barangay hall, religious institutions, fire stations, other government offices, and other commercial establishments. This is due to the increase in the number of population in Dagupan City. The construction of residential buildings and other buildings for the necessities and requirements of the local communities in their everyday living will also rise. 


\subsection{Buildings Vulnerability to Flood Hazard}

The vulnerability of the building refers to the building's inability to withstand the effects of disasters. In this study, the vulnerability of the buildings in the Dagupan floodplain was assessed through the comparison between the building's height and simulated flood depths. The analysis concluded that out of the 71,884 buildings, an increasing trend in the number of vulnerable buildings is predicted for the 5-, 25- and 100-year period at $1.35 \%, 6.13 \%$, and $12.93 \%$, respectively (not shown in the figures). Meanwhile, Figure 20 shows the number of buildings versus the flood hazard level during 5-year, 25-year and 100-year rainfall return periods in the city of Dagupan. In a 5-year rainfall return period, $98.65 \%$ ( 65,435 buildings) of the total number of buildings will be invulnerable to flood. While the number of vulnerable buildings is proportioned around $1.14 \%$ (816 buildings) for vulnerable to low flood hazard level, $0.22 \%$ (157 buildings) for medium level and a very little portion of $0.001 \%$ ( 1 building) will be vulnerable to high flood hazard level. Furthermore, in a 25 -year rainfall return period, the invulnerable number of buildings is about $93.87 \%(61,999$ buildings). In terms of vulnerability, 3.57\% (2567 buildings) will be under a low flood hazard level, 2.44\% (1754 buildings) will be under medium level and 0.12\% (89 buildings) will be under a high level. For the 100-year rainfall return period, a further drop to $87.07 \%$ (59,917 buildings) is expected to be invulnerable to flood. Apparently, for the 100-year rainfall return period, 6.42\% (4614 buildings) of the total number of vulnerable buildings will be under low flood hazard level, $6.08 \%$ (4368 buildings) will be under medium flood hazard level, and $0.44 \%$ (315 buildings) will be exposed to high flood hazard level.

The sum of buildings that show vulnerability to flooding is expected to increase throughout time according to the assessment using the building height and simulated flood depth height in Dagupan City. The following figures (Figures 21-23) are the illustrations of the locations of the buildings that are expected to be vulnerable to flood during the 5-, 25- and 100-year rainfall return period.

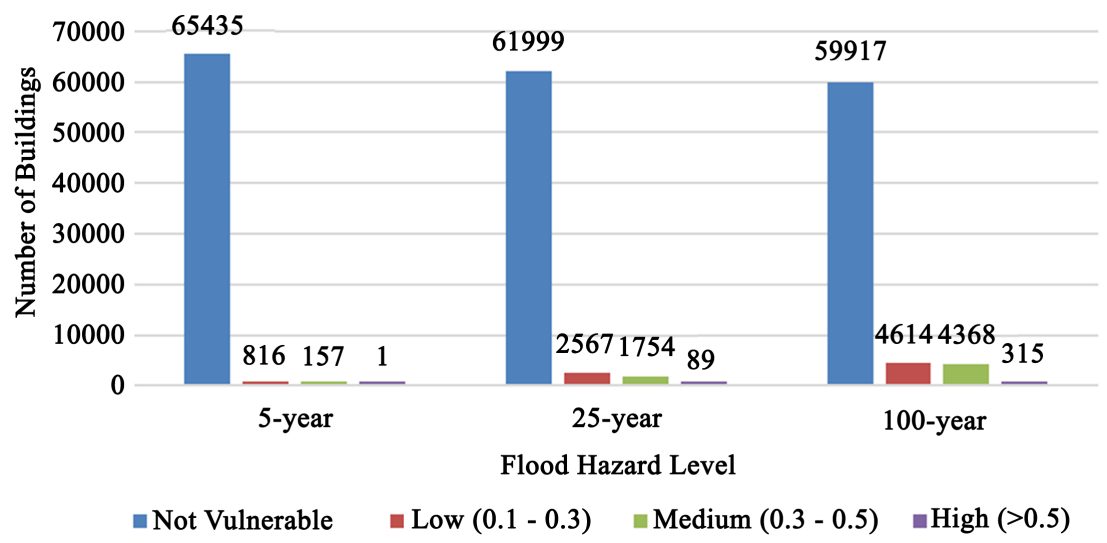

Figure 20. The number of buildings vulnerable to flood hazard in terms of height at different hazard levels. 


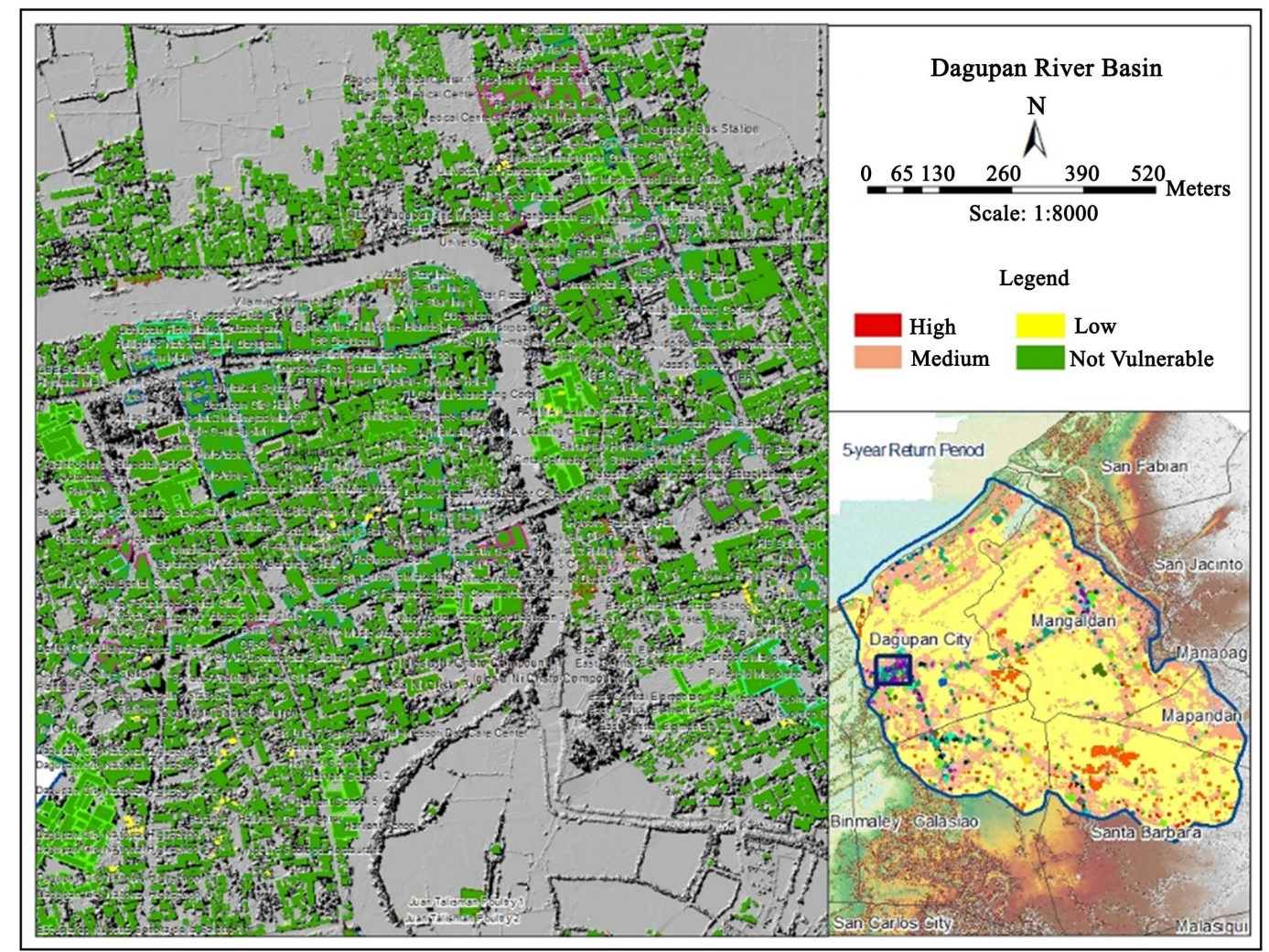

Figure 21. Location of buildings vulnerable to flood hazard at 5-year rainfall return period.

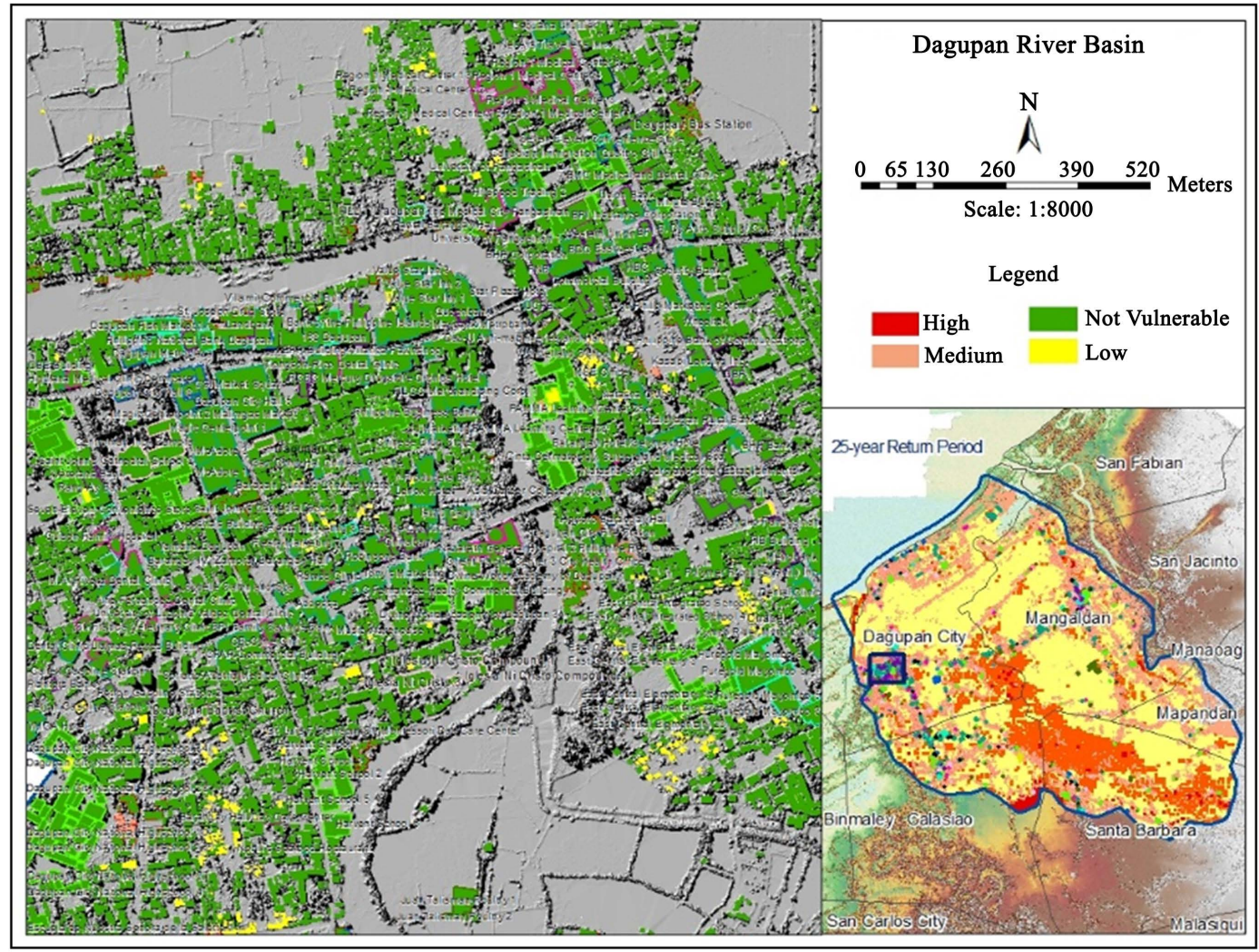

Figure 22. Location of buildings vulnerable to flood hazard at 25-year rainfall return period. 


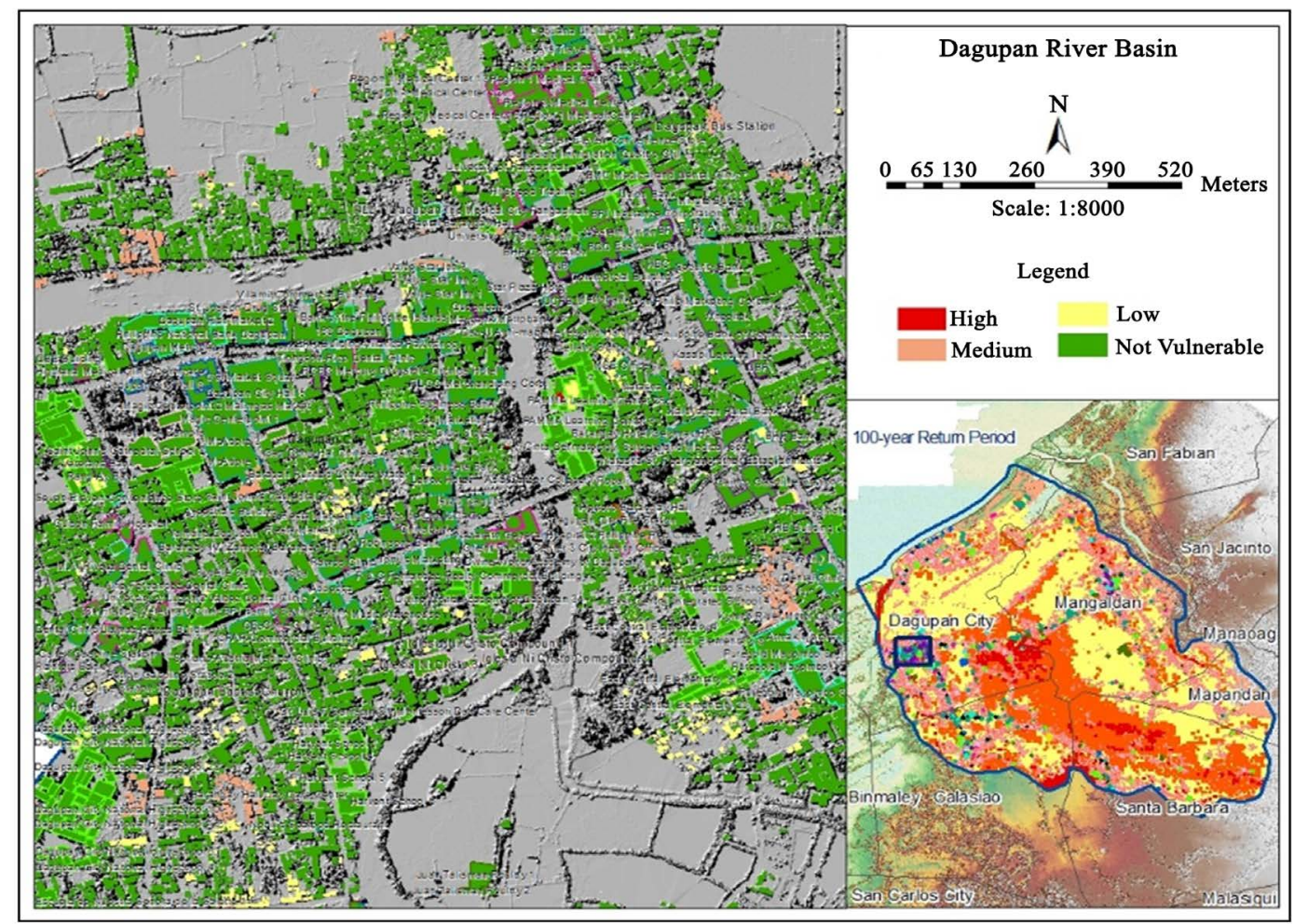

Figure 23. Location of buildings vulnerable to flood hazard at 100-year rainfall return period.

Figure 24 shows the vulnerability of buildings during the different flood hazard levels in Dagupan according to the different types of buildings. The number of buildings vulnerable to flood increases for 5-, 25- and 100-years of rainfall return periods. It can be observed from Figure 19 that the residential types of buildings are the ones that are affected by flood.

\subsection{Social Aspect}

\subsubsection{Temporal and Economic Analysis of the Buildings Present in Dagupan City, Pangasinan}

In a published Population Census from 1995 to 2000, an almost steady population growth increase was observed in Dagupan City, and the increase amplified starting from the millennium reaching up to 171,271 people in 2015 (Figure 25). PhilAtlas (Ecosystems Research and Development Bureau, 2015) mentioned that the recent Census in 2015 for Dagupan City corresponds to $5.79 \%$ of the total population of Pangasinan province.

Though the population of Dagupan City boomed from 1995 up until 2015, the total number of constructed buildings in Pangasinan has minimal increments throughout the years (2004-2016) (Figure 26). In contrast to the low increase in the number of residential buildings, when further investigated, the infrastructures, in fact, increased in total value for the same years (Figure 27). Even though Pangasinan is known for its four cities (Alaminos, Dagupan, Urdaneta, and San Carlos), records show that the province remained a home for around more than 2000 residential buildings in 2016 and about only less than 500 


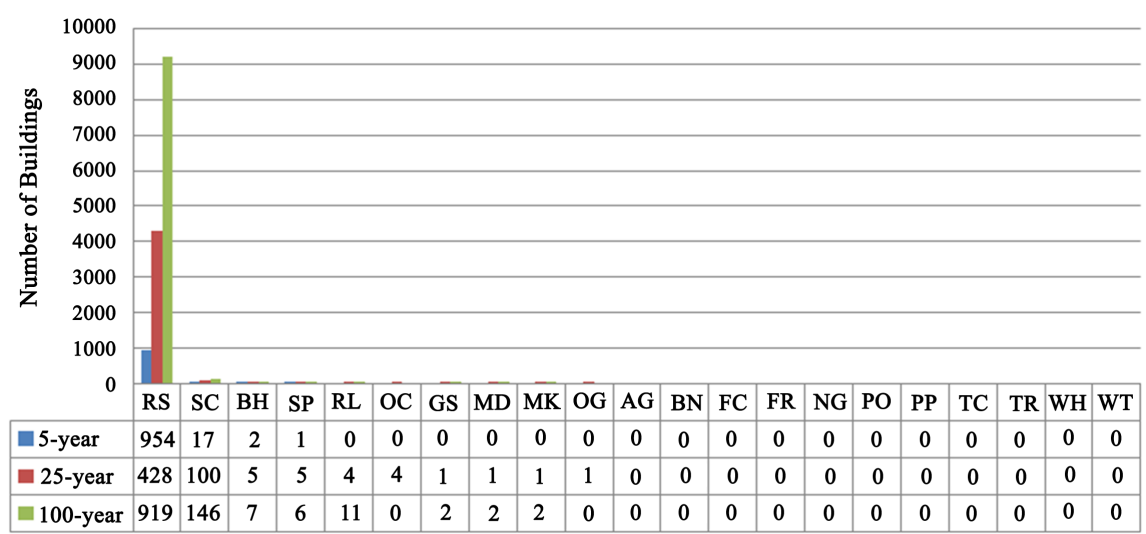

Type of Buildings

Figure 24. The number of buildings vulnerable to flood hazard according to type at varying return periods.

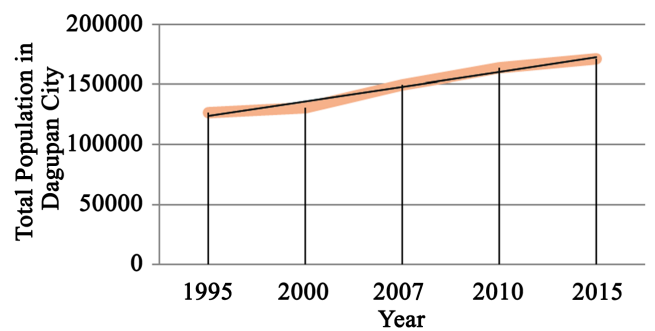

Figure 25. Total population density from 1995 to 2015 Census for the City of Dagupan.

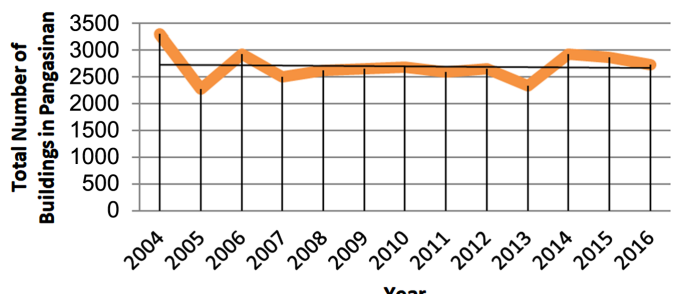

Figure 26. Total number of buildings in Pangasinan in 13 years.

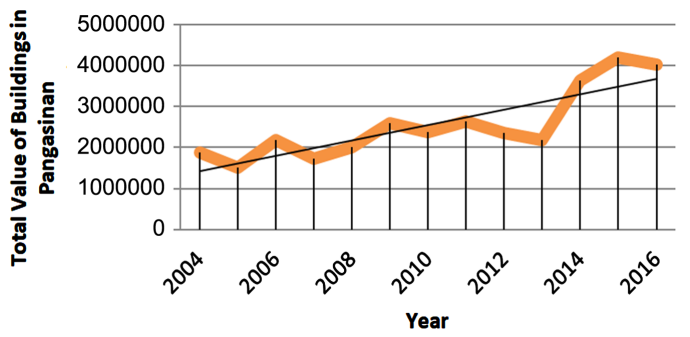

Figure 27. Total value of buildings in Pangasinan in 13 years.

non-residential buildings on that same year (Figure 28 and Figure 29). With more than 2000 residential buildings and more than 150,000 people in the record, this means that an occurrence of flood in Pangasinan is a threat that will largely affect the residents especially those that are inhabiting the low lying areas with close proximity to a body of water such as the river basin in Dagupan City. 


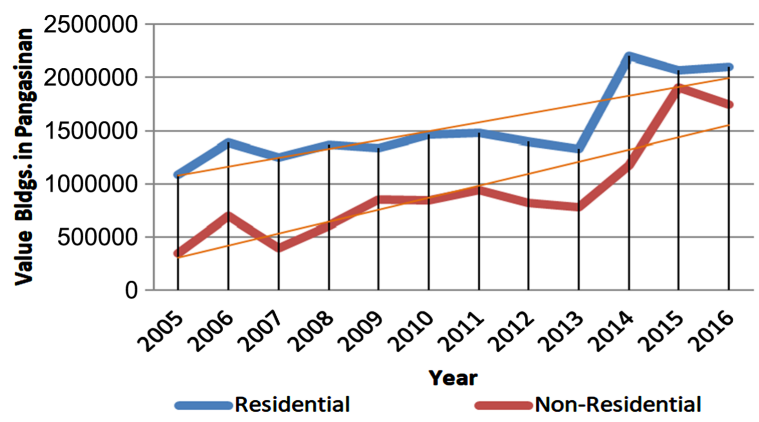

Figure 28. Total number of residential and non-residential buildings in Pangasinan in 13 years.

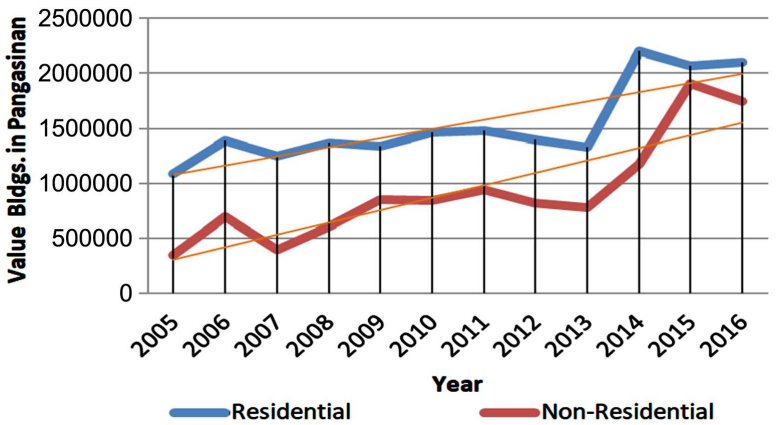

Figure 29. Total value of residential and non-residential buildings in Pangasinan in 13 years.

\subsubsection{Changes Observed and Natural Disasters Which Occurred in Dagupan (Sinocalan) River}

The one on one interview with the residents of Dagupan was carried out on September 15-18, 2015. The interview was conducted to have additional information regarding the history and to determine the current situation of the river. A total of 314 residents were interviewed along the river. The changes observed in the Dagupan (Sinocalan) River and the occurrences of natural disasters are as follows (Table 4 and Table 5).

Calamities were experienced by the residents near the Sinocalan River. The respondents said that they were usually hit by strong typhoons every year since the Philippines sit astride the typhoon belt, and the country suffers an annual onslaught of dangerous storms from July through October. Some typhoons found to be very destructive which were resulted in floods, overflowing of rivers, erosion, and hurricane. The calamities passed through the area often changed and affect the natural features of the river including erosion that caused the enlargement of the river width.

\section{Conclusion and Recommendations}

This study generated a 3D Building GIS database and exposure and vulnerability maps with a total of 71,884 buildings that were extracted from the flood plains of Dagupan River through the use of LiDAR technology and Geographic Information System. It was predicted that the majority of the buildings in the Dagupan 
Table 4. Changes observed in Sinocalan river in Dagupan, Pangasinan.

\begin{tabular}{ccc}
\hline Changes Observed & \% of respondents who observed such changes in specific parts \\
\hline Narrowing of River & $46 \%$ & $\begin{array}{c}\text { Midstream due to aquatic } \\
\text { wastes plus sedimentation }\end{array}$ \\
Widening of River & $33 \%$ & River and River mouth \\
High Turbidity & $21 \%$ & River mouth, due to aquatic wastes \\
Local Water District & For laundry and bathing 100\% & River and Coastal Areas \\
Deep well handpump & Drinking sources $100 \%$ & River and Coastal Areas \\
\hline
\end{tabular}

Table 5. Natural disasters in Sinocalan River and coastal areas in Dagupan, Pangasinan.

\begin{tabular}{ccl}
\hline Natural Disaster & \multicolumn{2}{c}{$\%$ of respondents who observed such changes in specific parts } \\
\hline Typhoon & $51 \%$ & Damage structures augmented by water dam release \\
Flood & $44 \%$ & $\begin{array}{l}\text { River mouth area and in conjunction with high tide and dam } \\
\text { water release, make the soil to lose tension }\end{array}$ \\
Landslides & $4 \%$ & $\begin{array}{l}\text { In upper areas during heavy rainfall } \\
\text { Tornado }\end{array}$ \\
\hline
\end{tabular}

flood plain will be exposed to flood in 5-, 25- and 100-year rainfall return periods. However, only a minimal proportion of the total buildings in the vicinity will be vulnerable to flood due to the building height.

The exposure and vulnerability maps produced in this study may help the residents and local officials to be prepared in the disaster that may happen during rainy seasons due to floods. Areas that will be severely affected by the flood on a 5-, 25- or 100-year rainfall return period are included in the produced hazard maps.

Due to the lack of other necessary data for the analysis during the time that this study was conducted, the analyses were only based on the height of the buildings extracted. It is recommended to expand the analysis where formal engineering decision analysis will be considered.

\section{Acknowledgements}

Sincere gratitude is due to the Department of Science and Technology (DOST) which funded this study. This work is an output of the Central Luzon State University (CLSU) Phil-LiDAR 1 project titled "LiDAR Data Processing and Validation in Luzon: Region III and Pangasinan (Region I)" of the "Phil-LiDAR 1: Hazard Mapping of the Philippines using LiDAR" program. The Digital Elevation Models (DTM and DSM) used were provided by the University of the Philippines Disaster Risk and Exposure for Mitigation (UP-DREAM)/Phil-LiDAR 1 Program. Heartfelt thanks to all CLSU Phil LiDAR 1 research assistants who helped in the production of 1D Flood Hazard Maps of Dagupan River and validation of this study. 


\section{Conflicts of Interest}

The authors declare no conflicts of interest regarding the publication of this paper.

\section{References}

Bureau for Crisis and Recovery (2010). Disaster Risk Assessment. United Nations Development Programme.

http://webcache.googleusercontent.com/search?q=cache:L7RVDqEC2hkJ:www.undp.o $\mathrm{rg} /$ content/dam/undp/library/crisis\%2520prevention/disaster/2Disaster\%2520Risk\%25 20Reduction\%2520-\%2520Risk\%2520Assessment.pdf\%3Fdownload+\&cd=1\&hl=en\&ct $=\mathrm{clnk} \& \mathrm{gl}=\mathrm{ph}$

Cardinoza, G. (2012). Dagupan under Water in 15 Years, Says Mayor. Inquirer.Net. http://newsinfo.inquirer.net/227501/dagupan-under-water-in-15-years-says-mayor

Dagupan City (2020). The City of Dagupan. https://www.dagupan.gov.ph/our-city/geography/

Dagupan City (2017). Dagupan Geography. Dagupan. https://www.dagupan.gov.ph/about-dagupan/geography

DENR Alaminos Regional Office (2013). Integrated Watershed Management Plan of Toboy-Tacnien River Watershed.

Ecosystems Research and Development Bureau (2015). Annual Report. Watershed and Water Resources Research Center Region 1 Ecosystems Research Station. San Fernando City, La Union. Department of Environment and Natural Resources.

Grünewald, F., \& Boyer, B. (2013). Lessons Learnt on Typhoons in the Philippines.

https://www.ready.gov/landslides-debris-flow

National Ocean Service (2015). What Is LiDAR? National Ocean Service. http://oceanservice.noaa.gov/facts/lidar.html

Philippine Statistics Authority (2010). PSGC: Dagupan City. Philippine Statistics Authority.

http://nap.psa.gov.ph/activestats/psgc/municipality.asp?muncode $=015518000 \&$ regcode $=01 \&$ provcode $=55$

Prevention Web (n.d.). Dagupan Nomination for the Web. Prevention Web. http://www.preventionweb.net/files/section/230_DagupanNominationfortheweb.pdf

Santillan, J., Makinano-Santillan, M., Cutamora, L., \& Serviano, J. (2015). 3D Building GIS Database Generation from LiDAR Data and Free Online Web Maps and Its Application for Flood Hazard Exposure Assessment.

Visperas, E. (2016). Dagupan River Gets Thumbs Up from Academe. PhilStar Global. http://www.philstar.com/science-and-environment/2016/12/22/1655649/dagupan-river -gets-thumbs-academe 